\title{
Application of Artificial Neural Network for Internal Combustion Engines: A State of the Art Review
}

\author{
Aditya Narayan Bhatt ${ }^{1} \cdot$ Nitin Shrivastava $^{1}$ CD
}

Received: 16 December 2020 / Accepted: 23 April 2021 / Published online: 3 May 2021

(c) CIMNE, Barcelona, Spain 2021

\begin{abstract}
The automotive industry is facing a crucial time. The transformation from internal combustion engines to new electrical technologies requires enormous investment, and hence the IC engines are likely to serve as a means of transportation for the coming decades. The search for sustainable green alternative fuel and operating parameter optimization is a current feasible solution and is a critical issue among the scientific community. Engine experiments are complicated, costly, and time-consuming, especially when the global economy is drastically down due to the COVID-19 pandemic and putting the limitation of social distancing. Industries are looking for proven computational solutions to address these issues. Recently, artificial neural network has been proven beneficial in several areas of engineering to reduce the time and experimentation cost. The IC engine is one of them. ANN has been used to predict and analyze different characteristics such as performance, combustion, and emissions of the IC engine to save time and energy. The complex nature of ANN may lead to computation time, energy, and space. Recent studies are centered on changing the network topology, deep learning, and design of ANN to get the highest performance. The present study summarizes the application of ANN to predict and optimize the complicated characteristics of various types of engines with different fuels. The study aims to investigate the network topologies adopted to design the model and thereafter statistical evaluation of the developed ANN models. A comparison of the ANN model with other prediction models is also presented.
\end{abstract}

\begin{tabular}{|c|c|c|c|}
\hline \multicolumn{2}{|c|}{ Abbreviations } & GEP & Gene expression programming \\
\hline ANN & Artificial neural network & GRNN & General regression neural network \\
\hline BFGS & Broyden-Fletcher-Goldfarb-Shanno method & $\mathrm{H}_{2}$ & Hydrogen \\
\hline $\mathrm{BP}$ & Brake power & $\mathrm{HC}$ & Unburned hydrocarbon \\
\hline BPNN & Back-propagation neural network & $\mathrm{HCCI}$ & Homogeneous charge compression ignition \\
\hline BSFC & Brake specific fuel consumption & $\mathrm{HCNG}$ & Hydrogen-enriched compressed natural gas \\
\hline CFD & Computational fluid dynamics & & engine \\
\hline CGP & Pola-Ribiere conjugate gradient & HORD & Hyper-parameter optimization-radial basis \\
\hline & Carbon monoxide & & function-dynamic coordinate search \\
\hline $\mathrm{CO}_{2}$ & Carbon dioxide & HRR & Heat release rate \\
\hline $\mathrm{CPO}$ & Crude palm oil & $\mathrm{IC}$ & Internal combustion \\
\hline ENN & Elman neural network & IMEP & Indicated mean effective pressure \\
\hline EGT & Exhaust gas temperature & LM & Levenberg-Marquardt \\
\hline EGR & Exhaust gas recirculation & Logsig & Logistic sigmoid \\
\hline FIP & Fuel injection pressure & LP-EGR & Low pressure cooled exhaust gas recirculation \\
\hline FES & Fuzzy expert system & MAPE & Mean absolute percentage error \\
\hline \multirow[t]{2}{*}{ GA } & Genetic algorithm & MIMO & Multi-input multi-output \\
\hline & & MISO & Multi-input single-output \\
\hline \multirow{3}{*}{\multicolumn{2}{|c|}{$\begin{array}{l}\triangle \text { Nitin Shrivastava } \\
\text { nitins@rgtu.net }\end{array}$}} & $\mathrm{ML}$ & Mult1-layer perceptron \\
\hline & & MRE & Mean relative error \\
\hline & & MSE & Mean square error \\
\hline \multirow{2}{*}{\multicolumn{2}{|c|}{$\begin{array}{l}\text { Department of Mechanical Engineering, University Institute } \\
\text { of Technology, Rajiv Gandhi Proudyogiki Vishwavidyalaya, } \\
\text { Bhopal, India }\end{array}$}} & NSGA & Non-dominated sorting genetic algorithm \\
\hline & & NOx & Oxides of nitrogen \\
\hline
\end{tabular}




$\begin{array}{ll}\mathrm{O}_{2} & \text { Oxygen } \\ \mathrm{PM} & \text { Particulate matter } \\ \mathrm{PPM} & \text { Parts per millions } \\ \text { PSO } & \text { Particle swarm optimization } \\ \text { PUNN } & \text { Product unit neural network } \\ \mathrm{R} & \text { Correlation coefficient } \\ \mathrm{R}^{2} & \text { Coefficient of determination } \\ \text { RBFNN } & \text { Radial basis function neural network } \\ \text { RMSE } & \text { Root mean square error } \\ \text { RSM } & \text { Response surface methodology } \\ \text { SCG } & \text { Scaled conjugate gradient } \\ \text { SFC } & \text { Specific fuel consumption } \\ \text { SPL } & \text { Sound pressure level } \\ \text { SVM } & \text { Support vector machine } \\ \text { Tansig } & \text { Tangent sigmoid } \\ \text { TOPSIS } & \text { Technique for ordering preferences by similar- } \\ & \text { ity to ideal solution } \\ \text { TPE } & \text { Tree-structured parzen estimator }\end{array}$

\section{Introduction}

The 1.1 billion light-duty vehicles and 380 million trucks are on-road vehicles worldwide. These numbers are likely to cross the 1.7 to 1.9 billion figure by 2040 . China and India are likely to see most of the rise. The current internal combustion-based automotive industry is uncertain about future technology. Hydrogen, electricity, and biofuels are the future of transport. The complete transformation of the internal combustion engines to new technologies is challenging due to socio-technological issues with tremendous capital investment. Transport electrification alone is unable to resolve the environmental challenges [1-4]. The safety reliability and the long term maintenance of electric vehicles is also a new concern $[5,6]$. Thus internal combustion engines are expected to serve the transportation sector for the coming decades $[1,7]$.

The future internal combustion engines have to deal with the legislative emission requirements, energy security, engine efficiency, affordability, and performance requirements of consumers. Internal combustion engines running on next-generation biofuels is the thrust area amongst the research community. Studies on bio fuelled engines showed improved performance, significant drop in $\mathrm{CO}$ emissions, unburned hydrocarbons, and particulate matters [8-18]. There can be no single best suggestive biofuel for the engine. The sustainable and affordable solution to use the biofuel depends upon the availability of the local feedstock or waste biomass, the properties of biodiesel, and the enhancement methods of improve the properties [2, 19-22].

Performance, combustion, emission, and other characteristic studies of the IC engine involve lots of parameters. Combustion phenomenon and exhaust emissions are very complex to understand and hence require several tests to find the relation between various parameters. High-precision instruments and equipment are required to measure the different operating parameters with these biofuels. These kinds of tests are expensive and time-consuming [23-25].

The recent economic crisis due to the global COVID-19 pandemic led the industry to huge revenue loss [26-28]. Social distancing, restricted research fundings has put the limitation on traditional research. So there is a need to develop a different alternative solution, which saves experimentation cost and time. In the current and long uncertain COVID-19 scenario, improved artificial intelligence-based research may dominate traditional research to reduce the cost and assist the social distancing by work from home culture. In the last few years, some computational modeling techniques are used to relate the different parameters of the engine and predict the different characteristics of the IC engines like performance, combustion, and emission and seem to be helpful due to its quite accurate predictions [29, 30]. In this approach, the artificial neural network is one of the possible techniques to predict the different characteristics of the IC engine with different sets of inputs.

\section{Artificial Neural Network}

The artificial neural network is the mainstream of artificial intelligence. Artificial intelligence is the development of intelligence and its analysis in the machine. An intelligent machine is a whippy noetic agent that perceives its environment and takes action that maximizes its opportunity of success at an arbitrary goal [31]. In the past decade, much work carried out using the ANN [32,33]. It can relate complex and non-linear problems, which may be complete or incomplete.

ANN finds its wide application in different streams such as engineering, science, pharmaceutics. Some of the important fields include sound and pattern detection, the prediction of the market trends, the bankrupt-ion, military targets, and mineral exploration sites [34-37]. Neural networks fend off the need for costly and impractical physical models, complex mathematical formulas, and computer models. Numerical or analog data that are difficult to handle due to the presence of many variables are easily handled by the neural network [38, 39].

ANN uses artificial neurons as that of biological neurons present in the human brain to process the data. Figure 1 presents the structure of a biological neuron. Coded data transfers in the brain from synapses to the axon via electrochemical media known as neurotransmitters. This coded information transfers to the set of neurons. A set of neurons arranged it into sub-systems; these sub-systems constitute the brain. Approximately there are around 100 
Fig. 1 Biological neuron [41]

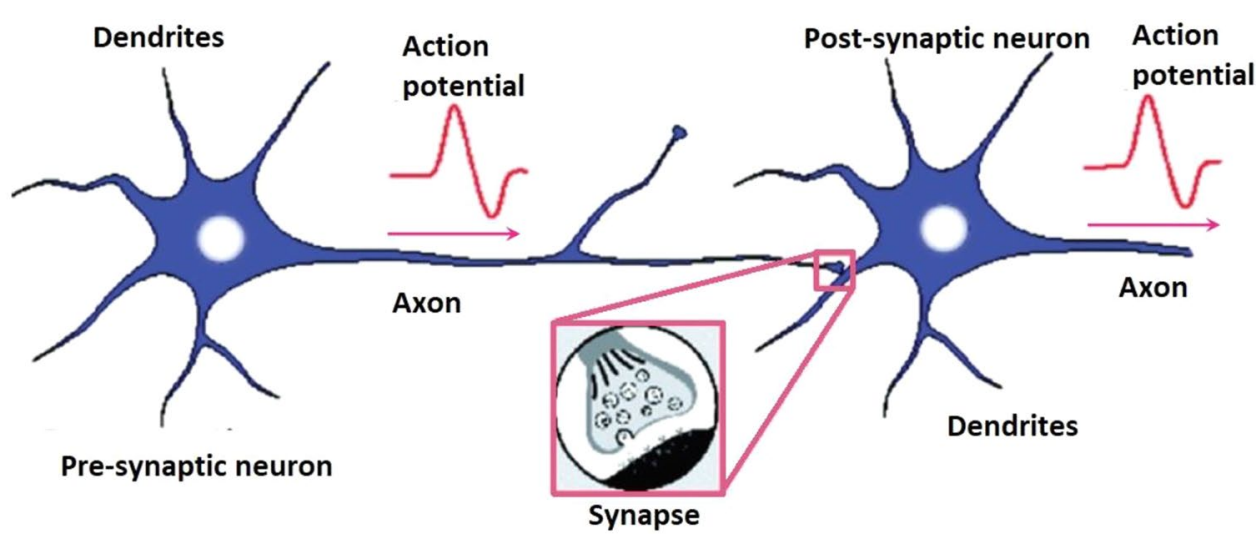

billion interconnected neurons present in the human brain. The artificial neural network has an inherent tendency like the human brain in the following respect [40]:

(i) Gaining knowledge from learning through experimental data.

(ii) Assign the required weights for storing them.

A schematic diagram of the ANN model is present in Fig. 2 that contains an input layer, hidden layers, an output layer, and a set of neurons in each layer. With the help of training, ANN gets the required information about the base problem by learning possible non-linear relationships, which are buried in the problem domain. It takes input from external sources such as experimental data and inter-relates them to get the required output [42]. It tends to relearn if any new set of data comes, and executes according to it, and predicts the new set of output $[40,43]$. For the prediction and analysis in engineering problems, ANN may be used as an alternative method [44]. To predict the multiple output variables, it accommodates multiple input variables. It has a different approach than the conventional approach of understanding the system without any information. A well-trained artificial neural network is more rapid than the established method to predict the result because it does not need to solve lengthy and complicated mathematical problems [45].

Neural network analysis uses a 'black box' technique to solve the problem so that the user needs not worry about sophisticated knowledge of mathematics [46]. The neural network stores the knowledge and information within the trained network, which can be easily accessed by the user. ANN provides a high level of exactness for earlier

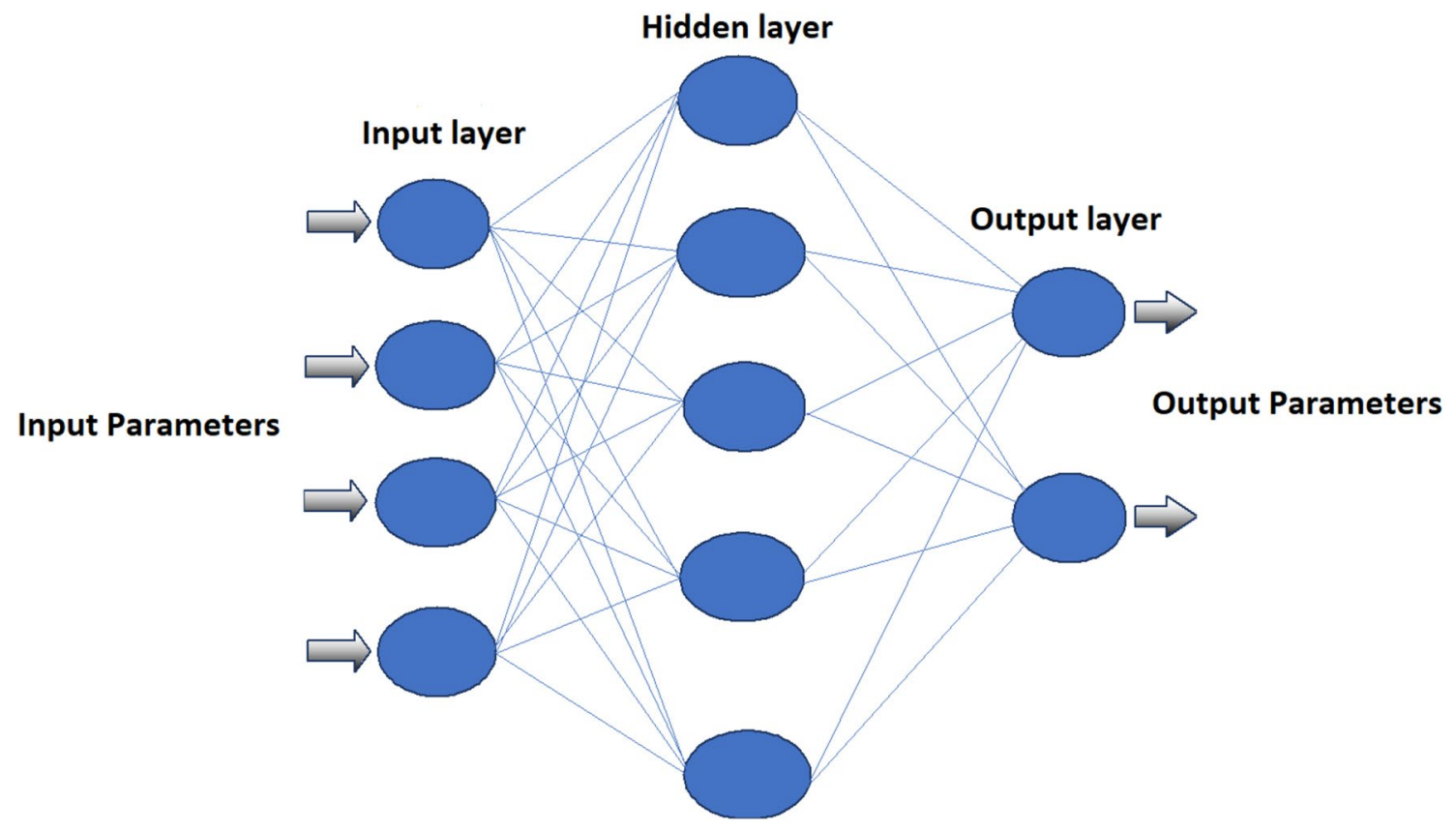

Fig. 2 A schematic diagram of the ANN [54] 
unobserved data sets of the base problem, which are not required in the 'training' process [47]. There could be some possible shortcomings comes when the neural network is used for solving complex problems. Most important of them is the data present in the base problem, which contains lots of information to train ANN, which may uniformly scatter all over the range of the system [48].

Different algorithms are available for training purposes such as Levenberg-Marquardt, conjugate gradient, and quasi-Newton [49]. The gradient descent algorithm is a slow learning process, whereas LM, quasi-Newton, and conjugate gradient algorithms are quicker and use standard numerical optimization techniques $[50,51]$. The complex nature of ANN may lead to computation time, energy, and space. Recent studies are centered on changing the network topology and design of ANN to get higher performance [52, 53].

\section{Modeling of Internal Combustion Engines}

The various studies adopting ANN as a tool in the field of the internal combustion engine are available. Most of these studies investigate the effect of alternative fuels, and diverse operating conditions on the performance, emission, noise, and other characteristics of the engine. The investigations were carried out experimentally or through computational fluid dynamics software. The generated data used to train the neural network-based models and, consequently, to predict the various characteristics of IC engines. The literature showed different approaches to predict the characterisitics. The present study compiled most of the literature and presented the applications of neural network modeling in IC engines, and the methodology adopted to develop the ANN model with their statistical efficiency. Studies carried out on different engines with various fuels are broadly categorized into three types of engines.

1. Spark Ignition engine

2. Compression ignition engine

3. Homogeneous charge compression ignition engine

The first two presented groups of the engine based on the traditional classification, i.e., the type of ignition, and the third is the newly developing HCCI engine.

\subsection{Spark Ignition Engine}

Studies on spark ignition are presented here in three categories. The first category deals with modeling studies using standard gasoline as fuel; the second deals with the alternative SI engine fuels, and the third involves the comparative studies of neural network modeling with other modeling techniques along with different operating parameter optimization studies. Various ANN models developed to forecast the performance, pollutants, misfire event, effect of combustion chamber coating, etc. are presented.

\subsubsection{Models with Standard Fuel}

This section presents the models using standard gasoline as fuel. The researchers investigated and predicted various engine operating characteristics. Initially, studies adopting the Multi-input single-output models are presented, and the later section deals with the multi-input multi-output models. In a study by Togun and Baysec [55], the authors predicted the SFC and torque of a gasoline engine as the output of ANN. Effect of Ignition advance, throttling status, and the engine speed investigated and considered as the input parameters. Each output parameter was predicted by a separate network. A 3-13-1 network architecture was opted to predict the engine torque, which consists of 3 input parameters, one hidden layer having 13 neurons, and one output layer. BSFC predicted through 3-15-1 network architecture. The study involves the use of logistic sigmoid as transfer functions, 10,000 epochs, and Levenberg-Marquardt as a learning algorithm. It includes the 63 experimental datasets to train and 18 to test the model. The torque prediction model resulted in the correlation coefficients of around 0.99 for training and testing, whereas for the prediction of BSFC, the values were 0.9971 and 0.98331 , respectively. The mean absolute percentage error for torque measurement was 0.2912 for training and 1.74 for the testing. BSFC prediction involves MAPE of 1.0186 and 2.7588, respectively.

Cay [56] developed three separate ANN models for predicting the BSFC, EGT, and effective power as an output parameter to examine the effect of three input parameters. The input of ANN consists of fuel flow, speed, inlet manifold temperature, torque, and water temperature. The algorithm used for the training of the network was back-propagation. A Levenberg-Marquardt and scaled conjugate gradient learning algorithms with 3 to 15 neurons in a hidden layer were compared. It concluded the use of SCG with 7 neurons. For the testing data, the mean error percent found less than $2.7 \%$, and RMSE values less than 0.02 . For both training and testing, the $\mathrm{R}^{2}$ value was found close to 0.99 .

Excess air coefficient affects the engine performance and emission drastically, and its determination is necessary for the efficient control of the air-fuel ratio. The widely used Step type and wideband lambda sensors, located on the exhaust pipe selected for this measurement. However, these sensors are very costly. Sahin [57] suggested the estimation of this coefficient with ionization current data using the secondary spark plug and different engine variables. The developed ANN model involves the excess air coefficient as an output and ignition angle, engine speed, and the peak ionization current with the location were the input parameters. 
Two hidden layers were selected. The network trained with two different training algorithms, and the result showed that the Scaled Conjugate Gradient algorithm was better than the Levenberg-Marquardt algorithm in both training and testing. The values of MAPE, $\mathrm{R}^{2}$, and RMSE, for testing, were $12.34723,0.99508$, and 0.04063 , respectively.

Many researchers predicted the characteristics of the engine using Multi-input multi-output models. Golcu et al. [58] studied the effect of variable valve timing on performance and fuel economy. The authors advance and retard the crank angle by 10 to 30 degrees and develop the ANN model using valve-timing and speed as inputs. Fuel flow and torque were chosen as the output data. A single hidden layer with 15 neurons opted. The back-propagation algorithm with logsig and purelin adopted as the transfer functions. The torque and fuel flow testing showed the RMSE of around $0.9 \%$ and $0.28 \%$, respectively.

Hazar and Gul [59] studied the result of piston and valves coating on an engine. $300-\mu \mathrm{m} \mathrm{Cr}_{3} \mathrm{C}_{2}$ plasma spray coating employed to examine the performance and emissions of the coated and uncoated engine. Experiments were performed at different engine speeds to train the ANN network. SFC, HC, $\mathrm{CO}, \mathrm{NOx}$, and EGT values of both the engine were recorded. A single hidden layer with 10 neurons was adopted. Tangent Sigmoid function selected for the hidden layer and LM as the learning algorithm. The regression value of output parameters found very close to 1 .

\subsubsection{Models with Alternative Fuels}

In search of the alternative fuel for better performance and improved emissions, researchers developed models to investigate the various alcohol blended fuels, different octane number fuels, hydrogen, etc. Initially, MISO based modeling studies are presented. Cay et al. [60] analyzed the ANN model for a methanol engine. Torque, speed, water temperature, inlet air temperature, fuel flow parameters were used as inputs while SFC, effective power, pressure, and EGT were predicted separately as outputs. The back-propagation algorithm with five neurons in a single hidden layer and logistic sigmoid function was adopted. Experimental data of a methanol fuelled engine was opted to train the ANN model. The coefficient of determination was found near to one, for training and testing data. RMSE and MAPE were less than 0.015 and $3.8 \%$ respectively for the testing data. In a similar study Cay et al. [61] developed a three-layered model to forecast SFC, air-fuel ratio, and emissions like CO and unburned hydrocarbon of the engine. One hidden layer with 5 to 15 neurons with BFGS, LM, RP, and SCG algorithms tested to forecast $\mathrm{BSFC}, \mathrm{AFR}, \mathrm{HC}$, and $\mathrm{CO}$ respectively. The best network structures for these parameters were 4-7-1, 4-11-1, 4-14-1, and 4-7-1, respectively. In comparison with the experimented data, the correlation coefficient was $0.998621,996,075,0.977654$, and 0.998382 respectively.

Kapusuz et al. [62], in their study, use methanol and ethanol blends with gasoline together and separately. The study was to optimize the use of methanol and ethanol share for the minimum SFC, maximum torque, and maximum power. Seventy data sets were used, which includes each ratio of ethanol and methanol in increments of 5 percent. These three parameters formed as inputs to ANN. Power, torque, fuel consumption rate, and BSFC were obtained as the separate outputs intended to achieve high success. The LM algorithm was used for this purpose. The weights and biases were update using the gradient descent with momentum backpropagation algorithm. The tansig function opted for the hidden layer due to the high success rate. The architecture for torque, power, fuel consumption per hour, and BSFC were 3-10-1, 3-10-1, 3-7-1, and 3-18-1, respectively. ANN gave the regression values of $0.9906,0.997,0.9974$, and 0.9312 for the torque, power, fuel consumption per hour, and BSFC, respectively. The study showed a mixture of $11 \%$ methanol with $1 \%$ ethanol gave the best results, whereas the mixture containing $2 \%$ ethanol gave the minimum BSFC.

Many researchers studied MIMO models; in this context, Kiani et al. [63] worked with four strokes, four-cylinder SI engine, and use ethanol-gasoline fuel. Torque, BP, and pollutants such as $\mathrm{CO}_{2}, \mathrm{NOx}, \mathrm{HC}$, and $\mathrm{CO}$ predicted with three input parameters viz; load, speed, and ethanol share. Two hidden layers with 25 neurons showed the highest correlation coefficient. The authors used the back-propagation technique with the Widrow-Hoff learning rule and compared the trainrp, traingdx, trainscg, and trainlm as training functions whereas the trainlm function was selected. The correlation coefficients were 0.96 and 0.99 for $\mathrm{BP}$ and torque, whereas, for $\mathrm{NO}_{\mathrm{X}}, \mathrm{HC}, \mathrm{CO}_{2}$, and $\mathrm{CO}$, values were $0.71,0.90,0.96$, and 0.98 , respectively. Najafi et al. [64] evaluated the use of bioethanol-gasoline blends in an engine. A 2-20-9 configured model developed to forecast the relation between volumetric efficiency, thermal efficiency, power, torque, BSFC, $\mathrm{CO}, \mathrm{CO}_{2}$, NOx, and $\mathrm{HC}$ emissions, using different combinations of ethanol and speed as inputs. 20 neurons in one hidden layer were selected. The Back-propagation algorithm opted to predict these results. The gradient descent rule was adopted to minimize the error. Amongst the trainrp, traingdx, trainscg, and trainlm functions, the trainlm function was adopted to train the network. The $\mathrm{R}$ values of the predicted results lie between 0.97 to 1 . MRE values were found between $0.46 \%$ to $5.57 \%$ and RMSE was found very low.

In another study, Yu and Arcakliog [65] tested ethanol blends with unleaded gasoline. The author performed the test on different ignition timing, compression ratio, density, and the relative air-fuel ratio. These parameters were fed as inputs to ANN architecture. Torque and SFC were calculated 
and taken as output parameters for the network. One hidden layer containing five neurons was selected. LM and SCG algorithms compared to train the model. LM found to give the least error. The logsig transfer function was selected. After testing, the $\mathrm{R}^{2}$ data for SFC and engine torque were 0.999915 and 0.999977, respectively. Similarly, Danaiah et al. [66] used a tert butyl alcohol-gasoline blend and developed a 3-1-10 network to forecast the various engine characteristics and found an excellent correlation among the experimental and forecasting results.

Sayin et al. [67] predicted thermal efficiency, SFC, HC, $\mathrm{CO}$, and exhaust temperature using fuels of three different octane numbers. 96 engine test run data generated with 95 , 93, and 91 octane number gasoline. The lower heating value of fuel, air inlet temperature, torque, and speed opted as the input parameters. The model involves the selection of one hidden layer with 15 neurons with tangent sigmoid as the transfer function. $70 \%$ out of the total engine test run data chosen for training and the leftover $30 \%$ data employed to test the performance. A back-propagation algorithm and the Levenberg-Marquardt function opted to adjust the weights. The predicted output parameters like BSFC, BTE, CO, HC, and EGT resulted in the mean relative error of $2.24 \%, 2.97 \%$, $3.64 \%, 6.66 \%$, and $1.41 \%$; root mean square error of $17.05 \mathrm{~g} /$ $\mathrm{kWh}, 0.51 \%, 0.04 \%, 1.41 \%, 19.66 \mathrm{ppm}$, and $2.96^{\circ} \mathrm{C}$; and a correlation coefficient of $0.994,0.992,0.992,0.996,0.983$ respectively.

Mehra et al. [68] carried out the ANN modeling of the hydrogen-enriched CNG engine. 'Hydrogen and CNG in a separate tank were mixed manually. A model developed to forecast the torque, $\mathrm{BSFC}, \mathrm{NOx}, \mathrm{CO}, \mathrm{HC}$, and $\mathrm{CH}_{4}$ using engine load, excess air ratio, spark timing, and HCNG ratio as inputs. The tansig and LM learning algorithms was adopted in the ANN structure. The obtained Correlation coefficient values were close to one.

\subsubsection{Model Comparison and Optimization Studies}

Researchers compared the engine characteristics predicted by the different neural network models and other soft computing methods based models. Some researchers carried out multi-objective optimization studies on the ANN predicted outputs with different optimization methods. In this context, Tasdemir et al. [69] investigated the engine characteristics of the gasoline engine. The authors compared the predicted results of the fuzzy expert system with ANN models. Hydrocarbon emission, SFC, torque, and power were selected as output parameters. Intake valve advancement and speed selected as inputs. The back-propagation algorithm with the tansig transfer function was adopted in the 2-60-4 ANN network model. The gradient descent was adopted as the learning function. The FES model was designed using 48 fuzzy rules and the Mamdani approach for fuzzy inference mechanism. Regression analysis in Matlab and t-test in SPSS used to compare the results of ANN and FES. Both the results are statistically very close to each other and also to the experimental data. Both methods are simple and fast in terms of the speed of computation. In another study, Tosun et al. [70] predicted the injection duration, SFC, and EGT at two different points using ANN and linear and non-linear regression analysis. The authors concluded the better accuracy of ANN than other regression methods.

Zhang et al. [71] studied the method to detect and diagnose the misfire in an engine using the group of Luenberger and the sliding mode technique. A Luenberger sliding mode observer opted for the estimation of engine combustion torque. The authors presented an ANN model based on the experimental misfire events data and obtained engine combustion torque. Three methods, including back-propagation neural network, Elman neural network, and Support vector machine, were applied and compared. The study showed the designed ENN was able to predict the misfire data more accurately in different test conditions than the other two methods. The running time of SVM found significantly lower than ENN and BPNN, whereas the running time of BPNN was found higher than ENN.

Jo et al. [72] studied the turbocharged gasoline direct engine, which involves the low-pressure cooled exhaust gas recirculation to curtail NOx emissions. The long path of LP-EGR leads to the transport delay, which leads to an inaccurate estimation of LP-EGR flow. Further, non-linear characteristics also make the estimation difficult. An accurate estimation of LP-EGR is required to enhance the fuel economy and for emission curtailments. An ANN model involving 12 combustion inputs like maximum engine pressure, IMEP, and 10 different mass fractions burnt in a certain range, used to precisely estimate the LP-EGR flow as an output. All the inputs normalized in the range of 0 to 1 . The LM based back-propagation algorithm was adopted. The three optimization algorithms viz HORD, TPE, and random search were compared to get the optimized value of hyperparameters. The result showed that the efficacy of all algorithms to search hyper-parameter was highly considerable. The results for all three algorithms showed the $\mathrm{R}^{2}$ values of more than 0.98 , and RMSE values smaller than $0.76 \%$.

Martinez et al. [73] developed a model to estimate the engine NOx emission by the use of injection timing, torque, intake pressure, speed, ignition point, and throttle data. The 6-7-9-6-1 network architecture with logsig as transfer function was selected. The model was modified with three objective functions using the Ant colony optimization. The optimization involves the sensitivity analysis using the hyper-volume metrics and the VIKOR method for decision making. The obtained correlation coefficient was close to one. 
A summary of the important studies are presented in Table 1.

\subsection{Compression-Ignition Engine}

This section presents the neural network modeling studies on the compression ignition engines using firstly, standard diesel fuel, secondly, alternative liquid and gaseous fuels, and thirdly, the comparative modeling and optimization studies.

\subsubsection{Models with Standard Fuel}

The studies on diesel engines with various operating conditions using standard diesel fuel are summarized. The few studies adopted multi-input single-output models to predict each engine parameter by a separate neural network. A performance map of the Mercedes Benz eight-cylinder diesel engine was studied by Celik and Arcaklioglu [76]. The authors predicted the SFC curve, fuel-air equivalence ratio, and EGT as separate ANN models. The engine power, engine speed, and water temperature were the inputs. Four neurons in a single hidden layer were adopted. Back-propagation with SCG and LM algorithm showed $\mathrm{R}^{2}$ close to 0.99. RMSE was smaller than 0.03. In a similar study [77], the fuel consumption of the mining truck was predicted by ANN using loading time, idle time to load, empty travel time, payload, idled empty time, loaded travel time as inputs. A 6-9-9-1 ANN architecture comprising 9 neurons each in two hidden layers was used and resulted in the MAPE of around 10 percent. Bietresato et al. [78] studied the predictive capability of ANN to assess the performance of the farm tractor indirectly. The authors predicted the BSFC and torque using indirect measures like EGT and motor oil temperature of four agriculture tractors. $\mathrm{R}^{2}$ values were close to 0.996 . The authors concluded the use of the Gaussian function over the sigmoidal function.

Exhaust valve temperature and the heat transfer coefficient between the valve and its seat were determined with two ANN models separately, by Goudarzi et al. [79]. Two temperatures at different points of the seat, as obtained from inverse heat problems, were selected as inputs to the models. Ten learning algorithms were compared and LM reported the best convergence characteristics. The model for predicting the exhaust valve temperature contained 15 and 7 neurons in two hidden layers, whereas the heat transfer coefficient model contained 10 and 5 neurons, respectively.

In a study on turbocharged diesel engine with the precombustion chamber, the result of speed, throttle-position, and injection pressure on the brake mean effective pressure, power, engine torque, fuel flow, $\mathrm{SFC}$, smoke, $\mathrm{CO}_{2}, \mathrm{SO}_{2}$, and NOx were investigated. An ANN model with three inputs viz; injection pressure, throttle position, and speed examined to forecast the performance and emissions separately. The test dataset fed to train and validate the model. A single hidden layer having 5 to 15 neurons for performance parameters, and two hidden layers with combinations of 8-7, 9-5, 9-7, 10-7 neurons for emission parameters were used. The back-propagation, along with the logsig transfer-function, was adopted. Three different training functions viz; LM, CGP, and SCG evaluated, and the authors reported the LM function as fastest, whereas the CGP function reported the highest number of errors. The result showed that $\mathrm{R}^{2}$, RMSE values were close to 0.99 , and 0.01and MAPE was less than 8.5. The study highly recommends the use of ANN only if the experiments are producing steady-state results. Otherwise, ANN may not be appropriate [80].

The studies based on multi-input multi-output models are also carried out by some researchers. Roy et al. [42] observed the consequences of varying EGR strategies on the common rail direct injection engine and developed an ANN model for EGR quantification and to enhance the onboard diagnostics. The model was used to predict the effect of load, diesel-injected, FIP, and EGR on the SFC, BTE, NOx, $\mathrm{CO}_{2}$, and particulate matter. A 4-10-10-5 structure of four inputs, five outputs with two hidden layers having ten neurons in each was adopted. The logsig as the transfer function, $\mathrm{LM}$ as the training algorithm, and minimum MSE as the loss function criteria considered. The model gave the high correlation coefficient value from 0.987 to 0.999; MAPE values varied from 1.1 to $4.57 \%$. Apart from the standard correlation coefficients, the authors studied the mean square relative error (MSRE), forecasting uncertainty (Theil uncertainty U2), Nash Sutcliffe Coefficient of Efficiency (NSE), and Kling-Gupta Efficiency (KGE). The values of MSRE and Theil uncertainty U2 were relatively low. KGE and NSE values were found highly in control, indicating the robustness of the developed model.

Some of the authors used the computation fluid dynamics generated data as the input of the neural network model. Nikzadfar and Shamekhi [81] studied the individual roll of 10 engine inputs on the BSFC, torque, NOx, and soot of 1.5 $\mathrm{L}$ diesel engine for better controlling and calibration purposes. Ten different engine input parameters include EGR rate, temperature and pressure of air, speed, the weight of primary and pilot fuel, exhaust and rail pressure, injection crank angle, and pilot retard. The authors developed the engine model using AVL boost simulation software using engine geometric and phenomenal properties. AVL- mixing control combustion model used for this purpose, which was then validated by experimental test data. The simulated engine model adopted for the development of a neural network model. Four thousand datasets were generated out of this engine model used for ANN modeling. Due to the nonlinear behavior of some of the output parameters, a two-stage multi-layer perceptron model was adopted. Both the models involve two hidden layers, the first contains ten neurons in 


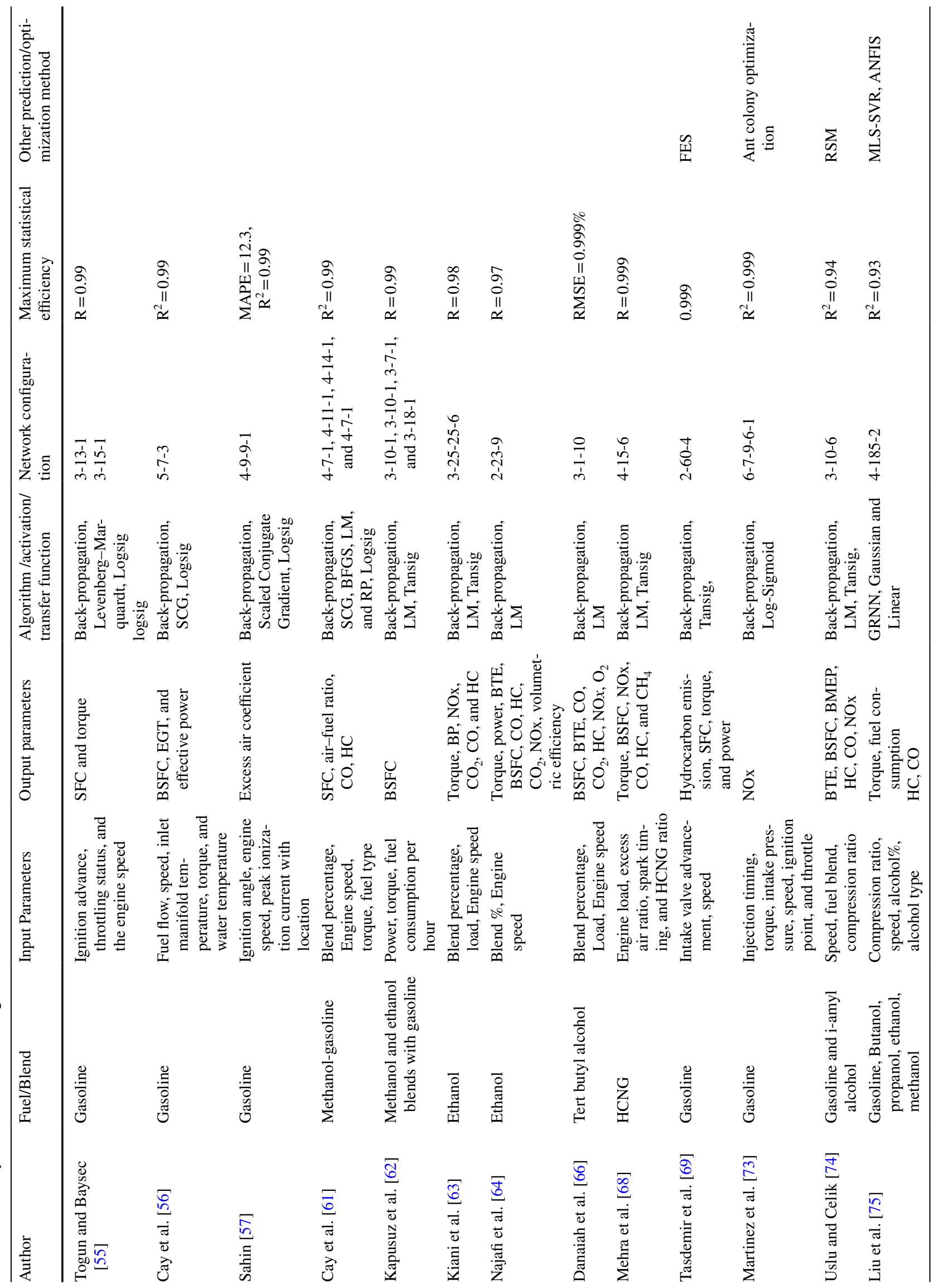


each layer whereas the second model contains ten and eight neurons in each layer. Exhaust temperature, torque, and aspirated air were the outputs of the first model. These outputs were used for the second stage model to forecast the soot and NOx. The study evaluated the individual role of these inputs on the outputs using perturbation sensitivity analysis. The authors concluded that the injected fuel mass significantly affected engine performance and emissions parameters.

\subsubsection{Models with Alternative Fuels}

Many studies investigate the variety of alternative fuels by adopting the neural network models to forecast the performance emission characteristics of CI engines. The studies presented are categorized into liquid and gaseous alternative fuels.

3.2.2.1 Liquid Fuels The researchers investigated the use of alternative liquid fuels like biodiesel of different origins, alcohols, etc. by the neural network models. Some authors initially present here, used the MISO models. Muralidharan et al. [82] analyzed and developed a model to forecast the emission, performance, and combustion parameters of the engine using waste cooking oil biodiesel. Three different ANN models with back-propagation algorithms utilized to predict parameters separately. The input parameters considered were different blend percentages, load, compression ratio, and crank angle. Trainbr, trainrp, traincgf, traingda, traingdx, trainscg, trainbfg, and trainlm functions compared with each other. The result showed the minimum convergence time and MSE value with the trainlm function. After testing the $\mathrm{R}^{2}$ for SFC, BTE, EGT, IMEP, BP, and mechanical efficiency found as 0.9982, 0.998, 0.9994, 0.9972, 0.9995 , and 0.9912 , respectively.

Gurgen et al. [83] studied the cyclic variability of the butanol-fuelled engine. The Coefficient-of- variance of IMEP for engine running on different fuel mixtures and different speeds were experimentally measured. The observed datasets were incorporated to design an ANN model to forecast the cyclic variability as an output parameter with fuel mixtures, and speed as inputs. SCG learning algorithm used to train the 2-11-1 ANN network architecture. The $\mathrm{R}^{2}$ value was in the range of 0.737 to 0.9677 .

Arumugam et al. [84] used a 4-2-1 configured ANN model to estimate the emission and performance characteristics separately for the rapeseed biodiesel fuelled engine. Different percentages of biodiesel blend, BP, BSFC, and EGT were the inputs to the neural network. The SFC is relatively the same for all diesel blends except B20R (20\% rapeseed methyl ester $+80 \%$ Diesel), which get a slightly higher reading than diesel. The obtained R-value was close to 1 and MRE less than 5\%.
The studies presented here onwards used MIMO models. The diesel engine performance using preheated crude palm oil was studied by Yusaf et al. [85]. The performance parameters were quite comparable to ordinary diesel, and break power is slightly higher than diesel. The $\mathrm{CO}$ emission was disappointing as its concentration in the exhaust was high, which indicates the incomplete combustion of the CPO. The power, $\mathrm{BSFC}, \mathrm{NOx}, \mathrm{CO}, \mathrm{CO}_{2}$, and EGT predicted through the neural network model, taking different percentage blend, engine speed as inputs, and back-propagation algorithm to teach the network. Initially, network weight and biases were initiated arbitrarily. Gradient descent rule used to minimize errors. The logsig function selected for the hidden layer and a 2-25-6 network configuration was selected. The study involves training the ANN by $80 \%$ out of the 40 sample data. Nearly accurate results as compared to experimental results observed with MSE of 0.0004 .

Kshirsagar and Anand [86] modeled the varying injection timing and pressure to predict engine performance using Calophyllum inophyllum methyl ester. Two different ANN model was developed, first with 4-16-3 architecture to forecast the performance parameters and second with 4-14-14-6 architecture to forecast the emission characteristics. Load, fuel blends, injection pressure, and timing were the inputs to both models. R, NSE, forecasting uncertainty values were in the range of 0.99879-0.99993, 0.990406-0.999802, and $0.011525-0.049462$, respectively. These values indicate the robustness and high effectiveness of the developed model.

Mega Motors Company, the largest car manufacturing unit in Iran, studied the BSFC, torque, CO, and $\mathrm{HC}$ emission of a two-cylinder engine running on waste cooking oil, and developed a model to predict these parameters based on the biodiesel blend and speed of the engine. Logsig activation function with a single hidden layer containing 25 neurons was selected. $\mathrm{R}$ values were near one for all outputs with MSE was 0.0004 [50].

In a study, a 6-49-15 ANN network architecture used for condition-based monitoring and fault detection of the vessel diesel engine. The model used for predicting fuel consumption and faulty conditions like faulty fuel injectors, clogged air cooler, clogged filter, polluted turbine. The data from propeller shaft torque, fuel oil flow meter, thermocouples, and pressure sensors selected as inputs. The model approximates the results close to the actual one [87].

To investigate the thermal barrier coated engine, Kumar et al. [88] used Lanthanum zirconate to coat the piston, valves, and cylinder head. Pongamia Pinnata biodiesel was tested in the study to analyze the BSFC, BTE, HC, NOx, and $\mathrm{CO}$. These parameters were predicted through the ANN model having network configuration 3-6-5, whereas coating, load, and fuel type took as inputs to ANN. For training, the back-propagation algorithm was adopted. The transfer function for the hidden and output layer was Tangent sigmoid. 
MSE and MRE of the predicted results were 0.002 and 6.8\%, respectively.

In another study, Lapuerta et al. [89] analyzed the effect of biodiesel on particulate matter emissions. A model was developed to estimate the quantity of insoluble and soluble particulates on different engine speeds and blend percentages. The LM non-linear fitting approach opted for training the network. The results showed that palmitic acid methyl esters mainly affect the insoluble particulate present in biodiesel. Oğuz et al. [90] used a 2-28-4 configured ANN architecture to forecast the performance characteristics of bioethanol-biodiesel fuelled engines. The torque, power, fuel consumption, and BSFC predicted with the help of engine revolutions and the fuel type as the inputs to the network. The tansig transfer function was selected. The values of training speed $(\beta)$ and learning ratio $(\alpha)$ were chosen as 0.3 . The reliability significance value for the predicted results was $99.94 \%$.

Shivakumar et al. [45] studied the consequences of varying fuel injection timing and compression ratio on an engine running on waste cooking. $\mathrm{BSFC}$ and $\mathrm{NO}_{\mathrm{X}}$ emission for biodiesel blended fuel found relatively higher than neat diesel, whereas smoke and $\mathrm{HC}$ emissions were relatively less. These results predicted through the developed ANN model. The algorithm used to train the model was back-propagation. The blend ratio, load, injection timing, and compression ratio selected as inputs, whereas exhaust temperature, energy consumption, and thermal efficiency as outputs parameters. The MRE for emission and performance characteristics are $8 \%$ and $5 \%$, respectively.

Ilangkumaran et al. [91] prepared diethyl ether blended biodiesel of fish oil. A model to forecast emission and performance parameters was developed. The model had one hidden layer with 20 neurons. Different load and percentage blend were inputs to the model. Correlation coefficients of BTE and EGT were found as 0.997 and 0.999, whereas, for exhaust emissions, it was 0.997 to 1 . Gharehghani and Pourrahmani [92] optimize the 36 combinations of water, biodiesel, and $\mathrm{ceO}_{2}$ nano-particles to minimize exhaust emissions. The optimum value determined by defining a new parameter known as the performance-evaluation-of-dieselengine (PEDE). An ANN model was developed to get the highest value of PEDE. The sensitivity analysis obtained the optimum value of PEDE's. Similarly, the effects of $\mathrm{CeO} 2$ nano-particle addition and consequent ANN model with 3-12-4 architecture with trainlm training rule showed a correlation coefficient close to 1 [93].

Manieniyan et al. [94] carried out the wear analysis of Mahua oil-fuelled diesel engine with hot and cold EGR. The authors predicted the wear elements present in lubricating oil, like $\mathrm{Fe}, \mathrm{Cu}, \mathrm{Co}, \mathrm{Zn}, \mathrm{Pb}$, and $\mathrm{Mg}$ as output parameters using the probabilistic neural network (PNN) and radial basis function neural network. The hot EGR, Cetane number, Cold
EGR, and lube oil time considered as inputs. The smoothing factor value of 0.8 and a hidden layer with 56 neurons gave the least MSE for the PNN model. The optimum number of centers for RBFNN was selected as 225 . RBF width was considered as 0.08 . The authors concluded that both models predicted the values close to the actual one. However, the RBFNN model predicts better than the PNN model.

In a study, 12 input parameters considered to predict the 12 output parameters simultaneously in an ANN model. The designed network model was to forecast the $\mathrm{CO}_{2}, \mathrm{CO}, \mathrm{HC}$, NO, Root mean square vibrations (vertical, lateral, and longitudinal directions), Kurtosis (vibration parameter in vertical, lateral, and longitudinal direction), torque, and power of engine running on biodiesel with alumina nano-particle. The 12 input parameters were LHV, fuel viscosity, density, fuel blend, speed, manifold pressure, fuel consumption, exhaust temperature, oil temperature, ambience pressure, relative humidity, $\mathrm{O}_{2}$ concentration. Architecture with 12-25-2512 structure having two hidden layers was used. $\mathrm{R}$ values were close to 1 [95]. Shanmugam et al. [96] prepare hybrid fuel by mixing ethanol and cottonseed biodiesel. A 2-31-6 configured ANN model was developed. Load and different blends of hybrid fuel were used as inputs, whereas BTE, $\mathrm{CO}_{2}, \mathrm{CO}, \mathrm{NOx}, \mathrm{HC}$, and smoke took as the outputs of ANN. The back-propagation algorithm and LM function adopted. The correlation coefficient values of the predicted results were in the range $0.975-0.999$.

In another study, Sakthivel et al. [97] investigate the IC engine fuelled with fish oil-based biodiesel. EGT, BTE, CO, $\mathrm{NOx}, \mathrm{HC}, \mathrm{CO}_{2}$, and smoke predicted with the help of the ANN model having network configuration 2-20-11. Backpropagation algorithm with trainlm function used to train the network. Load \% and types of fuel blend took as input parameters. The mean relative error and correlation coefficient of the predicted results were found as $0.02-3.97 \%$ and $0.957-0.999$, respectively. Similar results were obtained by other authors [98-100].

In another study, Canakci et al. [101] work on John Deere 4276T model engine fuelled with waste frying oilbased biodiesel to predict torque, load, cylinder pressure, thermal efficiency, mass flow, fuel flow, injection pressure, $\mathrm{CO}, \mathrm{NOx}, \mathrm{CO}_{2}$, EGT, smoke, and $\mathrm{HC}$ using five different neural networks. Firstly different environmental conditions, cetane numbers, and various fuel properties were considered as inputs, whereas fuel flow, air mass flow, injection pressure as outputs to the network. Secondly, all previous outputs, along with speed and fuel properties, were considered as inputs to predict various performance and emissions parameters. The third and fourth networks in a similar way considered to avoid statistical error values of injection pressure. Finally, to predict the output coming out of the first and second networks, a fifth network was used with the input of the first network. Back-propagation, LM, and SCG 
algorithms were used to train the network. Predicted results have $\mathrm{R}^{2}$ values of 0.99 , and the MAPE was less than five.

In a study to investigate the $n$ heptanes-diesel combustion in Ford 1.8L direct-injection diesel engine, a computation fluid dynamics based model developed. RNG k- $\varepsilon$ turbulence model to simulate the turbulent flows in the combustion chamber, Dukowicz model for heating and evaporation of droplets, stochastic dispersion model to simulate the interaction of turbulent eddies with particles, and finally Extend Coherent Flame model for turbulent mixing were adopted. An ANN model to predict the NOx, soot, and $\mathrm{CO}_{2}$ developed. The crank angle, pressure, equivalence ratio, temperature, $\mathrm{O}_{2}$ concentration, and liquid mass evaporated considered as input parameters. Levenberge Marquardt training algorithm with 6-18-3 architecture considered. The $\mathrm{R}^{2}$ values were $0.9951,0.9995$, and 0.9976 , for NOx, soot, and $\mathrm{CO} 2$, respectively [102]. In a similar study [103], the CFD simulation model was used to forecast the wall heat flux for an n-heptane fuelled diesel engine. In another study by Salam and Verma [104], a CFD modeling software DieselRK software was used to generate the microalgae fuelled engine dataset. Diesel-RK employs a multi-zone combustion model. A neural network model developed to forecast the emission, performance, and combustion parameters of an engine using the numerically simulated load, fuel blending, and injection pressure as inputs to the model. A 3-10-17 network architecture adopted. $\mathrm{R}$ values were close to 0.98 for all the predicted outputs.

3.2.2.2 Gaseous Fuels The various researchers developed the ANN models to study the alternative gaseous fuel in dual fuel mode. The MISO model studies are initially presented. Celebi et al. [105] analyze the acoustics and vibrations of different biodiesel with natural gas addition in an unmodified engine. Speed, cetane number, CNG flow rate, and density as the input parameters used for predicting the vibration and sound pressure level separately. The 4-4-1 and 4-5-1 network architectures were used to investigate the vibration and SPL, respectively. Purelin and Logsig transfer functions employed in the output and hidden layers, respectively. The model outcomes were very close to the experimental values.

ANN modeling of micro combined heat unit operating in CNG diesel dual fuel mode was carried out by Akkouche et al. [106]. Three different models developed to predict the airflow, pilot fuel flow, and exhaust temperature with 3-5-41, 3-3-5-1, and 3-5-3-1 network architecture, respectively, using biogas flow, methane contents, the power used as inputs. Purelin and Logsig transfer functions employed in the output and hidden layers, respectively. Gradient descent with momentum function selected as learning function. $\mathrm{R}^{2}$ values were close to 1 for all three models.

Javed et al. [107] predicted the noise of the engine running on biodiesel blended with zinc oxide nano-particles and $\mathrm{H}_{2}$ induction in dual fuel mode. Sound level in decibel with a 4-8-1 network predicted using the load, amount of nano-particles, biodiesel share, and hydrogen share as inputs with a regression coefficient of 0.99 .

The other researchers reported the use of the MIMO model for engine characterization. In a study, Javed et al. [108] examined an engine running on five different combinations of biodiesel with $\mathrm{H}_{2}$ induction. The study aimed to estimate the BTE, BSFC, EGT, NOx, $\mathrm{HC}, \mathrm{CO}, \mathrm{CO}_{2}$, and $\mathrm{O}_{2}$ at various loading conditions, biodiesel ratio, and $\mathrm{H}_{2}$ share. A three-layered 3-16-8 network configuration was used, where different load, biodiesel blend, and the amount of $\mathrm{H}_{2}$ selected as inputs. The data normalized between the ranges of 0.1 to 0.9 . The 63 experimental data (approximately $70 \%$ ) used to train the network, 13 datasets (approx 15\%) used to validate, and the remaining 13 data sets used to test the whole model. A combination of seven different training algorithms and five various training functions investigated. LM learning algorithm with tangent sigmoid and logarithmic sigmoid transfer functions yields the best result. MSE, MAPE, and overall regression coefficient of the model were $0.0011,4.863 \%$, and 0.9936 , respectively, with a training time of $78.135 \mathrm{~s}$.

A predictive model to investigate the capability of ANN for the CNG dual-fuelled engine developed by Yusuf et al. [109]. BSFC, BP, BTE, EGT, and emission parameters were investigated as the outputs using engine speed and CNG $\%$ as inputs. 22 neurons in a single hidden layer with LM training function were selected. Correlation Coefficients for output parameters were from 0.92 to 0.99 .

The vibrations of an engine fuelled with hydroxyl (HHO) gas-biodiesel examined by Uludamar et al. [110]. HHO gas introduced via the intake manifold in varying amounts. An ANN model designed to forecast the consequences of cetane number, heating value, $\mathrm{HHO} \%$, and speed on the vibration characteristics. Two neurons in the hidden layer gave satisfactory results. The obtained Correlation coefficient was close to one.

Syed et al. [111] in a similar study, compared the seven learning algorithms in combination with three transfer functions to evaluate an ANN model developed for hydrogen diesel dual-fuel mode engine. A comparative matrix with Seven training algorithm viz; traingdx, trainlm, trainrp, traingda, traincgf, trainbfg, and trainscg along with three transfer functions viz; purelin, logsig, and tansig were prepared for 16 data sets. The matrix reveals that the quasi-Newton backpropagation and tansig-tansig transfer function found the best amongst other algorithms.

Taghavifar et al. [112] predicted the convective heat transfer coefficient of the engine head, piston walls, and cylinder liner of the hydrogen-fuelled diesel engine. In this study, a CFD based model designed to generate the data. An ANN model developed with liquid mass evaporated, equivalence 
ratio, and temperature as inputs. A 3-17-3 network configuration was selected, which yield the RMSE value of 9.13.

\subsubsection{Model Comparison and Optimization Studies}

This section is divided into two kinds of studies. The first part involves the comparative studies of the neural network models and with other predictive models. The latter part includes the ANN modeling and optimization of engine parameters by applying the different optimization techniques.

Esonye et al. [113] evaluated the emissions and performance of the Perkins diesel engine with different blends of African pear seed biodiesel. Multi-input and multi outputANN model designed to forecast the BSFC, BTE, HC, CO, and NOx emissions using the fuel blend, speed, and load as the input parameters. A single hidden layer with seven neurons along with Tan-sigmoid as transfer function was selected. The correlation coefficients were between 0.9 and 0.99. The authors also applied the Nelder Mead downhill optimization simplex method, which is generally used for multidimensional optimization. The model predictive equation of Nelder Mead was used to obtain various solutions. A comparison between ANN and Nelder mead predictive models was presented. The $\mathrm{R}^{2}$ values for BTE, BSFC, CO, NOx, and HC by the ANN model were 0.998, 0.811, 0.730, 0.601 , and 0.842 respectively, Whereas Nelder mead predictive model showed the values of 0.999, 0.974, 0.996, 0.985, and 0.998 respectively. Hence, it demonstrates the supremacy of the Nelder mead method over the ANN.

Shamshirband et al. [114] carried out a comparative study of different models to predict the exegetic variables of the engine using expanded polystyrene waste blended with biodiesel. Seven parameters viz; exergy transfer rate to coolant, fuel exergy rate, exergy rate of exhaust gas, exergy efficiency, exergy transfer rate to ambient, exergy destruction rate, and sustainability index examined using different engine speed, load, and biodiesel percent and polystyrene contents as inputs. An ANN-based prediction model compared with a support vector machine-based prediction model coupled with quantum particle swarm optimization (SVMQPSO), radial basis function (SVM-RBF), firefly algorithm (SVM-FFA), and discrete wavelet transform model (SVMWT). Results showed that the SVM-WT model showed superiority over the other four approaches. $\mathrm{R}^{2}$ and $\mathrm{R}$ values were more than 0.9979 and 0.9989 , proving the fidelity of the model. However, in another study Yildirim et al. [115] predicted the engine emissions, vibration, the noise of engine blended with different biodiesels, and dual-fuelled hydrogen induction through ANN and SVM. The authors reported that the ANN outperforms the SVM.

Redel-Macías et al. [116] used a 1/3 octave band analyzer to measure the combustion noise of the bio-fuelled engine.
A predictive model was developed for the biodiesel combustion noise where power, speed, blend, diesel noise, and 1/3 octave frequency selected as inputs. An ANN model was compared with the two polynomial regression models. Two response surface models include the one with interaction terms and another one without it. Neural network models studied were product unit neural network and a hybrid of PUNN with radial basis function (PUNN + RBFNN). ANN models were found better than response surface models. It observed that the noise predicted by the hybrid model and PUNN were close to each other. The authors recommend the use of pure PUNN due to its simplicity.

Aghbashlo et al. [117] developed the models to forecast the exegetic performance of engine running on diesel biodiesel blend using ANN, genetic programming, extreme learning machine, and extreme learning machine-with wavelet transformation. Fuel exergy, exergy efficiency, cooling water exergy, exhaust gas exergy, ambient exergy, exergy destruction, and sustainability index were the seven output parameters predicted by the models. Whereas biodiesel percent expanded polystyrene wastes contents, load and speed were the four input parameters. The authors reported the yield of closest and accurate prediction by extreme learning machine-with wavelet transformation method, followed by extreme learning machine, ANN and genetic programming. A similar study was carried out to compare the three different models and to forecast the engine emissions and performance using diesel-nano-particle blended fuel. Wavelet neural network (WNN), back-propagation neural network (BPNN), and non-linear autoregressive with exogenous input (NARXNN) were the models compared. All the models predicted the result very close to actual results; however, the authors concluded that the WNN with stochastic gradient algorithm (WNN-SGA) performed better than the other two models [118].

ANN and GEP based models were used to estimate the engine emissions and performance opting EGR. GEP is a population-based evolutionary algorithm. $\mathrm{CO}_{2}, \mathrm{NOx}$, PM, BSFC, and BTE were the outputs of the GEP model, whereas the load, EGR, fuel-injected, FIP selected as inputs. The large chromosomes were tested to minimize the error. The ratio of correlation coefficients of GEP to the ANN found more than one for all the predicted parameters, which indicates that the GEP is more accurate than ANN [119].

Instantaneous exhaust emissions of $\mathrm{NOx}, \mathrm{CO}_{2}$, particle number in nucleation mode, particle number in accumulation mode, and the geometric mean diameter of particles were predicted and compared, using ANN and genetic algorithm based symbolic regression method. Torque, speed, acceleration, air temperature, airflow, fuel consumption, and boost pressure were the inputs to models. The authors concluded that both models predicted the emissions accurately; however, NOx prediction by the 
symbolic regression method and $\mathrm{CO}_{2}$ prediction by ANN was found better than other methods [120].

Researchers optimized the outputs of the ANN model by different optimization techniques. Diesel, blended with castor oil biodiesel, was examined in a turbocharged engine by Etghani et al. [121]. Based on the experimental dataset, the authors designed an ANN model to forecast power, BSFC, PM, NOx, $\mathrm{CO}$, and $\mathrm{CO}_{2}$ using biodiesel percent and engine speed data. A 2-15-6 network consisting of fifteen neurons in a hidden layer selected. LM learning algorithm, logistic sigmoid transfer functions with 20,000 epochs considered. The output of the model was optimized considering the six objectives, i.e., maximize the $\mathrm{BP}$ and minimize the BSFC, $\mathrm{CO}, \mathrm{CO}_{2}, \mathrm{NOx}$, and PM. The modified NSGA-II method, employing the $\varepsilon$-elimination algorithm considered for optimization. The best trade-off solution of the six objective functions was determined by the TOPSIS method.

Krishnamoorthi et al. [122] analyzed the straight vegetable oil blended with diethyl ether on different compression ratios, EGR rate, and engine speeds. Consequently, the ANN model was developed and optimized. NOx, smoke, $\mathrm{CO}, \mathrm{HC}, \mathrm{CO}_{2}$, BTE, and BSFC were the output parameters forecasted by ANN using the load, compression ratio, and speed as inputs. A 3-12-7 architecture with LM training function was selected. $\mathrm{R}$ values range from 0.91 to 0.99 . The RSM based optimization method considered to maximize the engine performance parameters and minimize the engine exhaust emission parameters. In another similar study by the same authors [123], ANN modeling was adopted to forecast the engine parameters. The particle swarm optimization, along with RSM was considered for investigating the effect of compression ratio and EGR. Results concluded that the ANN-PSO-RSM approach provided better results with considerable accuracy.

Channapattana et al. [124] tested the Honne biodiesel on various compression ratios, injection timings, and pressure. An ANN model was designed to forecast the emissions and performance parameters at optimum operating conditions as obtained by the genetic algorithm. Weighted multiobjective genetic algorithm-based optimization was carried out to enhance the performance and emission curtailment simultaneously. The optimum results obtained were adopted to forecast performance and emissions. Four training functions viz; traingdx, trainlm, trainrp, trainscg compared, and trainlm function reported the least error.

Tertiary blends of diesel kerosene and ethanol were prepared and examined by Bhowmik et al. [125]. ANN model designed to forecast the BTE, energy consumption, $\mathrm{CO}, \mathrm{HC}$, and NOx using the load, kerosene, and ethanol blend. A 3-9-5 network topology was found to give the best results. The multi-objective response surface methodology (MORSM) was adopted to give the optimum result.
Roy et al. [126] examined the emission and performance trade-off of the CNG dual-fuelled engine. An adaptive merit function (AMF) designed for BSFC, PM, and NOx trade-off. An ANN meta-model was designed to establish a correlation between the control variable and the objective function. Load, CNG energy share (CES), and FIP were selected as the decision variable. The study involves the Latin Hypercube sampling scheme as the design of experiment strategy. A Particle swarm optimization technique was employed for the optimization purpose. On different loading conditions, the authors reported 2.7 to $9.9 \%$ higher AMF than the best experimental operations. A similar study with hydrogen dual-fuel in diesel engine under varying EGR strategies was carried out by Banerjee et al. [127]. Multi-objective particle swarm optimization on the ANN meta-model platform was adopted to enhance the performance-emission trade-off of the dual-fuel operation.

Deb et al. [128] developed an ANN model to predict the performance and emission parameters of the diesel engine using hydrogen in dual fuel mode. 2-15-15-6 network architecture, along with logsig-tansig activation function, was used. The model was evaluated based on Theil U2, NSE, and KGE values apart from traditional evaluation criteria, which proved the robustness of the developed model. A fuzzy approach implemented to achieve a multi-performance characteristics index (MPCI) value for optimization. Nine fuzzy rules were defined, and the highest value of MPCI was selected to obtain optimum fitment in the transfer function of the model.

Diesel-CNG dual-fuel engine investigated to prepare an MLP-ANN model. CO and NOx emissions predicted using CNG mass flow rate, diesel flow rate, intake temperature, speed, power as inputs. Experimental and neural network model uncertainties calculated. The $\mathrm{CO}$ and NOx were forecasted with the 5-13-1 and 5-14-1 architectures, respectively. The NSGA-II approach obtained the optimal decision variable based on concerning emissions. Crossover and Mutation probability was selected as 0.7 and 0.4 , respectively, with a population size of 50 . The Pareto optimal front was obtained for CO and NOx trade-off [129].

A summary of the important studies are presented in Table 2.

\section{3 $\mathrm{HCCl}$ Engine}

Homogeneous charge compression ignition engines are the modified form of compression ignition engines which utilizes the concept of using homogeneous charge as used in SI engines rather than heterogeneous charge used in CI engine. It can be more beneficial in terms of performance and emissions. Limitations of the HCCI engine using diesel-ethanol blends at higher loading conditions studied by Bahri et al. [133]. The relation between the combustion 
noise level and cylinder pressure was studied, and after that, an ANN noise level (ANL) model was developed to estimate it. Experimental datasets were generated at different steady-state and cyclic loading conditions. The max peak pressure and three pressures at a different crank angle used as inputs of ANN and noise level as output. A 4-20-1 network architecture was selected, and the obtained $\mathrm{R}^{2}$ was 0.99. In an earlier similar study, the same authors [134] detected the misfire event in ethanol fuelled HCCI engine with five different pressure inputs. Three types of misfires were considered in the study, namely, low temperature, fuel cut off, and high dilution (ultra-lean air-fuel mixture). Four hidden layers with ten neurons were selected. 7800 cyclic data used in the model to detect the misfire in the engine with 100\% accuracy. Bahri et al. [135], developed a similar model for detecting the ringing operation of the HCCI engine with ethanol and $n$-heptanes.

Rezaei et al. [136] analyze HCCI engine performance with butanol and ethanol separately and developed ANN models to predict various parameters like BTE, in-cylinder pressure, IMEP, HRR, NOx, CO, and HC. The fuel blend and equivalence ratio were the input parameters of each model. The authors compared the two neural network models based on feed-forward and radial basis functions. Both feed-forward and RBF model predicted the performance with less than 4\% MAPE. The feed-forward network proved simple and less complicated, whereas a radial basis function-based neural network took less training time.

Maurya and Saxena [137] predicted the ringing characteristics of a hydrogen-fuelled HCCI engine on varying operating and combustion conditions. The ringing intensity predicted as the output of the two different ANN models. The first model involves the combustion parameters as input, whereas the second involves the operating parameters. The combustion parameters studied were combustion phasing, peak pressure, peak temperature, and combustion duration. The speed, equivalence ratio, and temperature of the inlet valve opted as operating parameters. The results were compared with the kinetically simulated model. It was observed that the ANN results were very accurate and the computation time was very less. Mean square error of 4.17 and 2.21 observed with a combustion-based model and operating parameter based model, respectively.

Predicting the start of combustion is very crucial for determining the engine characteristics of the HCCI engine. The model to detect the start of combustion was developed by Taghavi et al. [138]. Three models opting for MLP, RBF, and NARX were compared. A genetic algorithm was used in this study to optimize the network architecture. GA fairly improved the regression coefficient of MLP and RBF models from 0.8965 to 0.96166 , and 0.7623 to 0.83991 , respectively. The NARX predicted result showed the best regression coefficient and was very close to one. It also reduced the computational time of the NARX model from 3.12 to $0.46 \mathrm{~s}$.

In a study, Anarghya et al. [139] investigated the HCCI engine using methanol, different blends of isooctane with $\mathrm{n}$-heptanes (PRF), at a different speed, and air temperatures in ANSYS fluent 3D simulation plate-form. The Zimont turbulent combustion model, $\mathrm{k}-\omega$ SST viscous model, and emission model of fluent used. Consequently, a radial basis neural network using the Gaussian activation function was developed. The IMEP, heat release rate, pressure release rate, $\mathrm{CO}, \mathrm{NOx}$, and $\mathrm{HC}$ were the predicted output parameters, whereas the air-fuel ratio, PRF percent, methanol, crank angle were the input parameters. ANN-GA method was adopted to optimize the weights and biases. The authors compared RBFNN and ANN-GA models and observed that ANN-GA models gave better results and close to experimental values.

A summary of the important studies are presented in Table 3.

\section{Conclusion}

This paper presents a brief review of different studies on the application of the artificial neural network and the methodology adopted in solving the complex problems of the internal combustion engine. The various problems were divided based on the type of engine, and the fuel used. It includes the problems of SI, CI, HCCI engines using traditional, and alternative fuels like biodiesel, alcohol, and gaseous fuels in dual fuelling. Literature showed the use of different ANN models like multi-input single-output and multi-input multioutput approach. The paper profoundly covers the methodology for developing the different ANN models and their statistical analysis for evaluation.

The various application studies involve the performance and emission predictions, modeling for valve timing, EGR rate estimation, knock intensity detection, noise prediction, maintenance of ships, misfire detection, wall flux estimation, heat transfer coefficient modeling, engine wear determination, and optimization problems. The various comparative studies also discussed to compare the different prediction and optimization models in terms of their accuracy, convenience, and computation time. In general, ANN was found to be convenient over other methods due to its simplicity and give considerable statistical efficiency.

The multi-input multi-output model was found more convenient than the multi-input single-output model. The Back-propagation with the Levenberg-Marquardt learning algorithm using a single hidden layer is commonly employed for considerable accuracy and convergence speed to determine most of the engine characteristics. The number of neurons in the range of 10 to 20 in a hidden layer and 


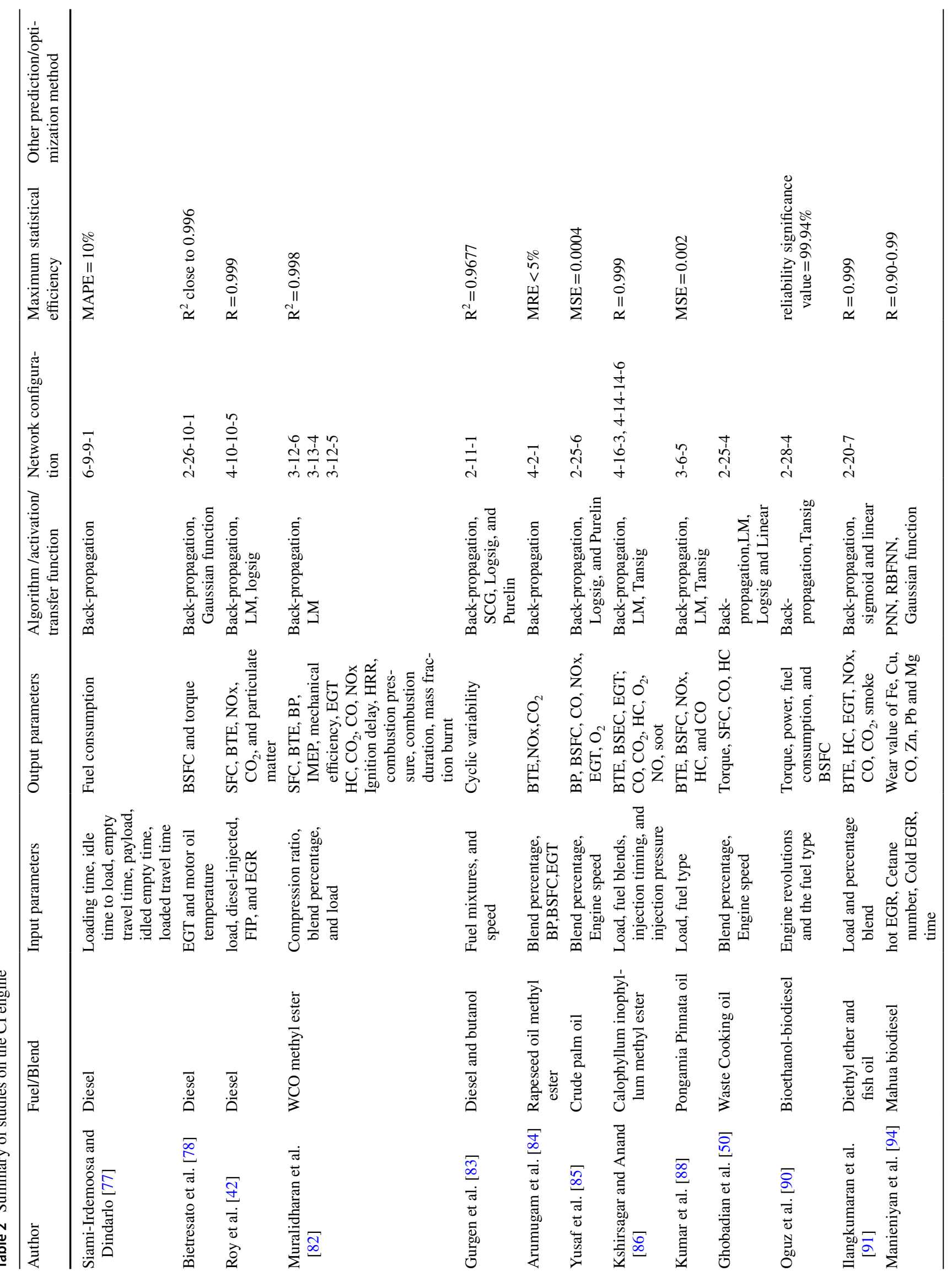




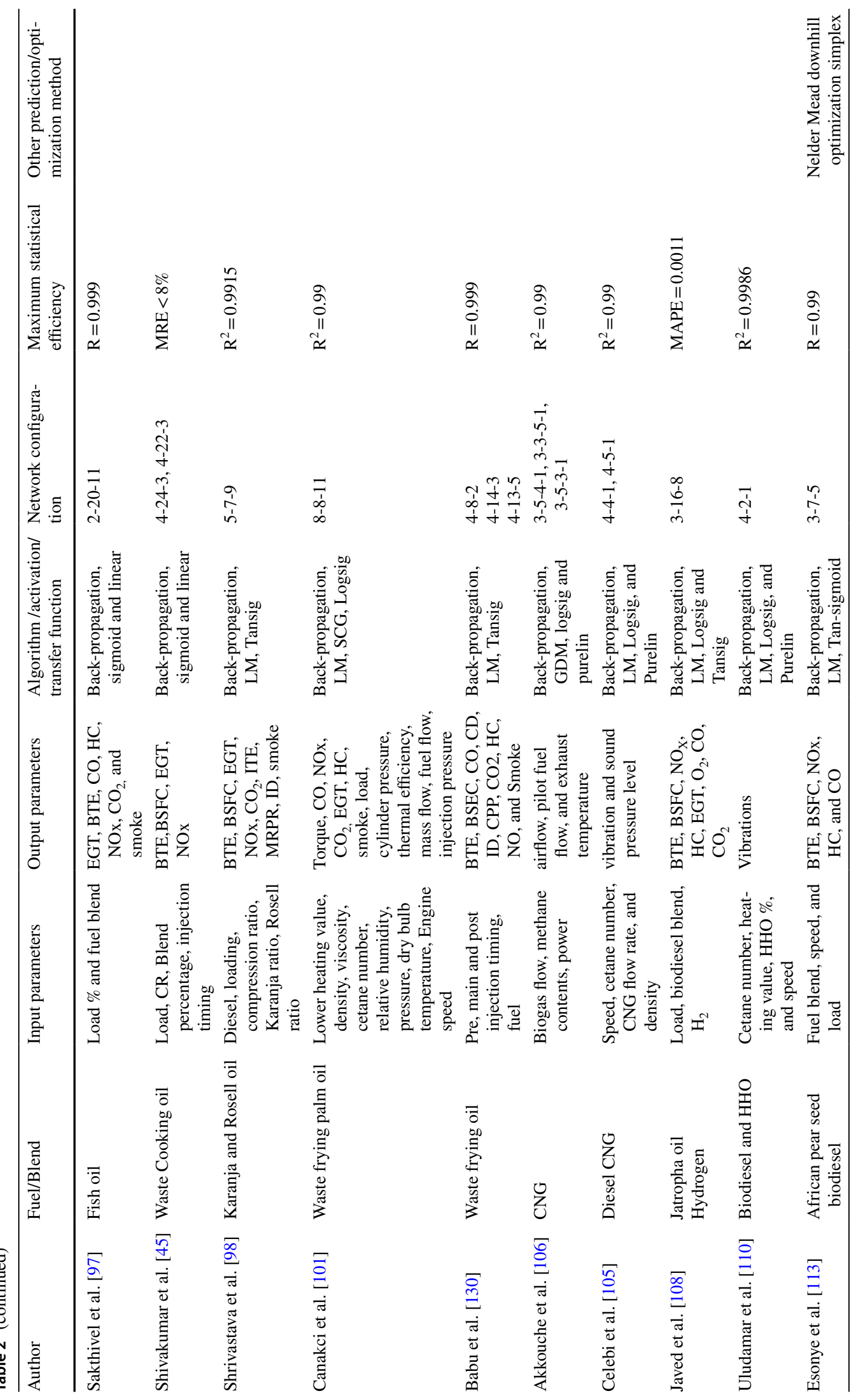




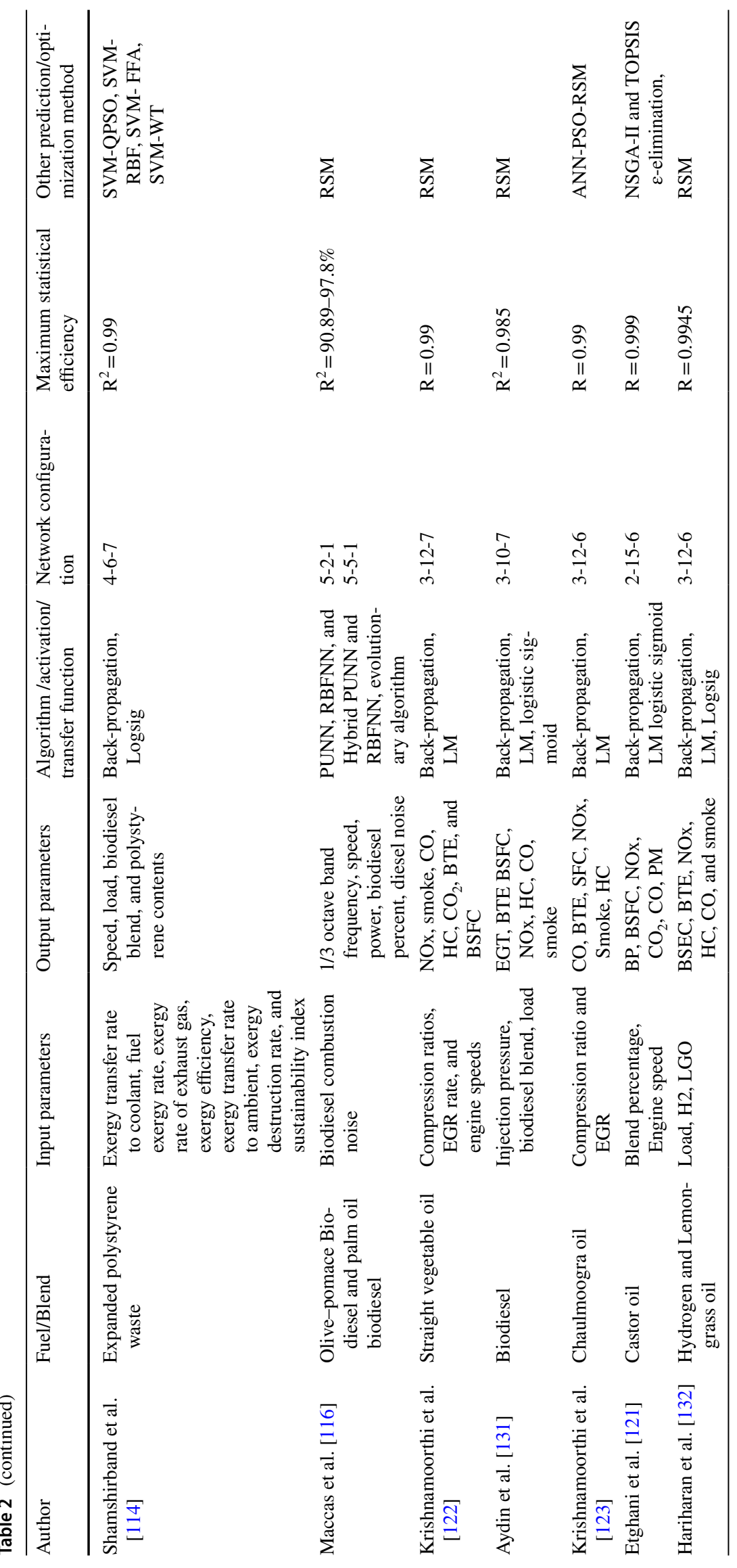




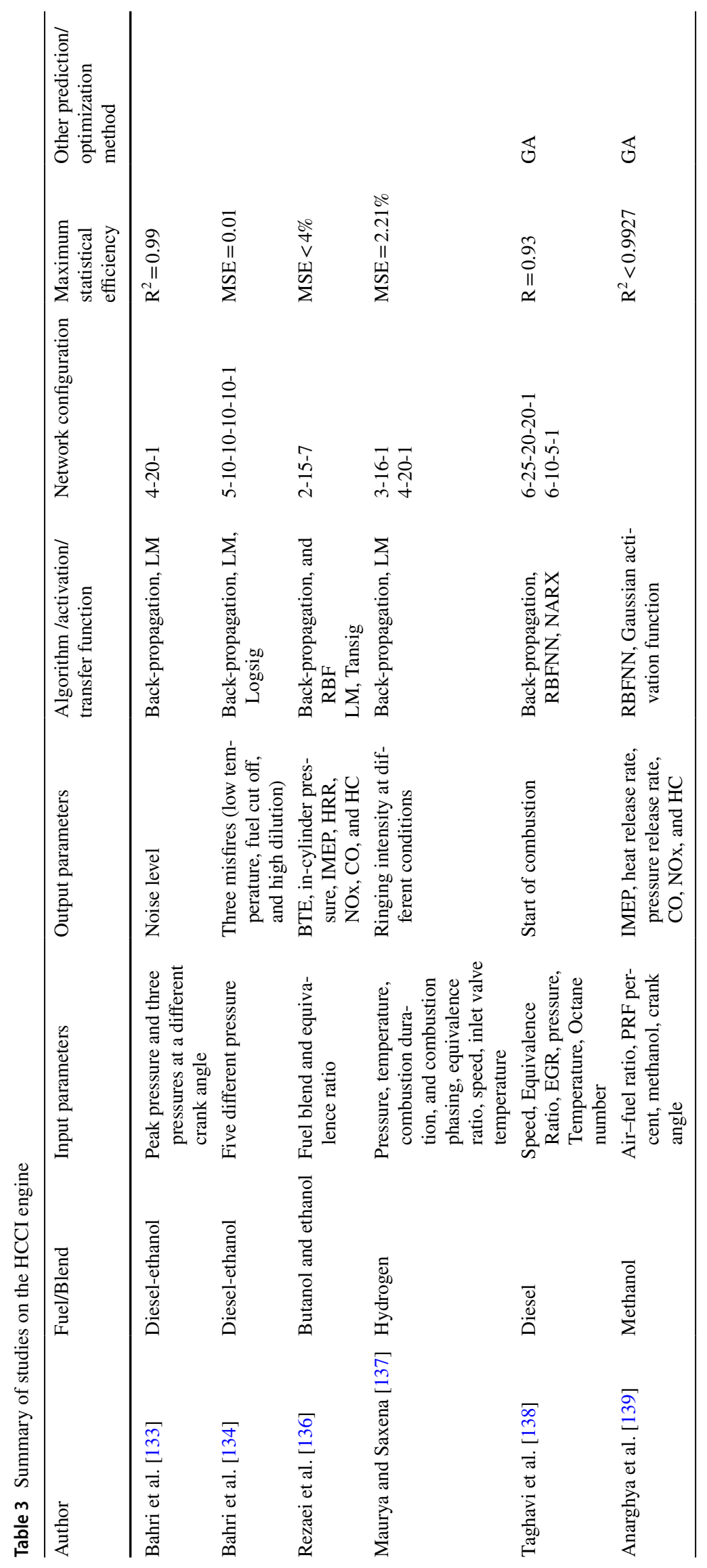


logarithmic sigmoid and tangent sigmoid transfer function found to give optimum results. This review shows that ANN can be efficiently used to predict complex engine performance, combustion, and emission characteristics and helps in a cost-effective search for sustainable alternative fuel with enhanced engine characteristics.

\section{Future Scope}

A wide variety of literature available on the prediction of engine characteristics with different test conditions using the artificial neural network. However, prediction studies incorporating most of the fuel properties along with test parameters can be future scope. The combustion chamber modification, particulate matters particle size estimation, is one of the critical areas missing in the literature.

Training the neural network is time-consuming, further comparative studies on the different networks, Deep neural network involving a higher number of hidden layers, recurrent neural network, convolutional neural network are therefore recommended.

\section{Declarations}

Conflict of interest The authors declare that they have no conflict of interest.

\section{References}

1. Kalghatgi G (2019) Development of fuel/engine systems-the way forward to sustainable transport. Engineering 5:510-518. https://doi.org/10.1016/j.eng.2019.01.009

2. Tsita KG, Kiartzis SJ, Ntavos NK, Pilavachi PA (2019) Next generation biofuels derived from thermal and chemical conversion of the Greek transport sector. Therm Sci Eng Prog. https:// doi.org/10.1016/j.tsep.2019.100387

3. Vandepaer L, Cloutier J, Amor B (2017) Environmental impacts of Lithium Metal Polymer and Lithium-ion stationary batteries. Renew Sustain Energy Rev 78:46-60. https://doi.org/10.1016/j. rser.2017.04.057

4. Huang B (2018) Recycling of lithium-ion batteries: recent advances and perspectives. J Power Sources 399:274-286. https://doi.org/10.1016/j.jpowsour.2018.07.116

5. Zhen X, Wang Y, Liu D (2020) Bio-butanol as a new generation of clean alternative fuel for SI (spark ignition) and CI (compression ignition) engines. Renew Energy 147:2494-2521. https:// doi.org/10.1016/j.renene.2019.10.119

6. Alonso Raposo M, Ciuffo B, Ardente F et al (2019) The future of road transport-implications of automated, connected, lowcarbon and shared mobility

7. Kalghatgi GT (2015) Developments in internal combustion engines and implications for combustion science and future transport fuels. Proc Combust Inst 35:101-115. https://doi.org/ 10.1016/j.proci.2014.10.002
8. Daraei M, Thorin E, Avelin A, Dotzauer E (2019) Potential biofuel production in a fossil fuel free transportation system: a scenario for the County of Västmanland in Sweden. Energy Procedia 158:1330-1336. https://doi.org/10.1016/j.egypro. 2019.01.327

9. Quiroz-Pérez E, Gutiérrez-Antonio C, Vázquez-Román R (2019) Modelling of production processes for liquid biofuels through CFD: a review of conventional and intensified technologies. Chem Eng Process Process Intensif 143:107629. https://doi.org/ 10.1016/j.cep.2019.107629

10. Karthickeyan V, Thiyagarajan S, Geo VE et al (2019) Simultaneous reduction of NOx and smoke emissions with low viscous biofuel in low heat rejection engine using selective catalytic reduction technique. Fuel 255:115854. https://doi.org/10.1016/j. fuel.2019.115854

11. Veza I, Said MFM, Latiff ZA (2019) Progress of acetonebutanol-ethanol $(\mathrm{ABE})$ as biofuel in gasoline and diesel engine: a review. Fuel Process Technol 196:106179. https://doi.org/10. 1016/j.fuproc.2019.106179

12. Shrivastava N (2017) Experimental investigation of performance, emission, and noise parameters of water-emulsified Karanja biodiesel: a prospective Indian fuel. J Braz Soc Mech Sci Eng 39:1009-1017. https://doi.org/10.1007/s40430-016-0581-z

13. Shrivastava N, Shrivastava D, Shrivastava V (2018) Experimental investigation of performance and emission characteristics of diesel engine running on jatropha biodiesel with nanoparticels as additives. Int J Green Energy 15:136-143. https://doi.org/10. 1080/15435075.2018.1428807

14. Shrivastava N, Varma SN, Pandey M (2013) Experimental investigation of diesel engine using EGR and fuelled with Karanja oil methyl ester. Int J Sustain Eng 6:307-315. https://doi.org/10. 1080/19397038.2012.749310

15. Sarıdemir S, Etem Gürel A, Ağbulut Ü, Bakan F (2020) Investigating the role of fuel injection pressure change on performance characteristics of a DI-CI engine fuelled with methyl ester. Fuel. https://doi.org/10.1016/j.fuel.2020.117634

16. Ağbulut Ü, Sarıdemir S (2018) A general view to converting fossil fuels to cleaner energy source by adding nanoparticles. Int J Ambient Energy. https://doi.org/10.1080/01430750.2018.15638 22

17. Sarıdemir S, Ağbulut Ü (2019) Combustion, performance, vibration and noise characteristics of cottonseed methyl ester-diesel blends fuelled engine. Biofuels. https://doi.org/10.1080/17597 269.2019.1667658

18. Dwivedi G, Jain S, Sharma MP (2011) Impact analysis of biodiesel on engine performance-a review. Renew Sustain Energy Rev 15:4633-4641. https://doi.org/10.1016/j.rser.2011.07.089

19. Verma P, Sharma MP, Dwivedi G (2016) Impact of alcohol on biodiesel production and properties. Renew Sustain Energy Rev 56:319-333. https://doi.org/10.1016/j.rser.2015.11.048

20. Verma P, Sharma MP, Dwivedi G (2016) Evaluation and enhancement of cold flow properties of palm oil and its biodiesel. Energy Rep 2:8-13. https://doi.org/10.1016/j.egyr.2015.12.001

21. Dwivedi G, Sharma MP (2014) Prospects of biodiesel from Pongamia in India. Renew Sustain Energy Rev 32:114-122. https:// doi.org/10.1016/j.rser.2014.01.009

22. Dwivedi G, Sharma MP (2014) Impact of cold flow properties of biodiesel on engine performance. Renew Sustain Energy Rev 31:650-656. https://doi.org/10.1016/j.rser.2013.12.035

23. Shrivastava N, Khan MZ (2017) Application of soft computing in the field of internal combustion engines: a review. Arch Comput Methods Eng. https://doi.org/10.1007/s11831-017-9212-9

24. Wong PK, Tam LM, Li K, Vong CM (2010) Engine idle-speed system modelling and control optimization using artificial intelligence. J Automob Eng. https://doi.org/10.1017/CBO9781107 415324.004 
25. Kannan GR, Balasubramanian KR, Anand R (2013) Artificial neural network approach to study the effect of injection pressure and timing on diesel engine performance fueled with biodiesel. Int J Automot Technol 14:507-519. https://doi.org/10.1007/ s12239

26. Haleem A, Javaid M, Vaishya R (2020) Effects of COVID-19 pandemic in daily life. Curr Med Res Pract. https://doi.org/10. 1016/j.cmrp.2020.03.011

27. Madurai Elavarasan R, Pugazhendhi R (2020) Restructured society and environment: a review on potential technological strategies to control the COVID-19 pandemic. Sci Total Environ. https://doi.org/10.1016/j.scitotenv.2020.138858

28. Nicola M, Alsafi Z, Sohrabi C et al (2020) The socio-economic implications of the coronavirus and COVID-19 pandemic: a review. IJS Publishing Group Ltd

29. Karonis D, Lois E, Zannikos F et al (2003) A neural network approach for the correlation of exhaust emissions from a diesel engine with diesel fuel properties. Energy Fuels 17(5):1259-1265

30. Traver ML, Atkinson RJ, Atkinson CM (1999) Neural networkbased diesel engine emissions prediction using in-cylinder combustion pressure. SAE Pap 1

31. Hutter M (2005) Universal artificial intelligence

32. Agwu OE, Akpabio JU, Alabi SB, Dosunmu A (2018) Artificial intelligence techniques and their applications in drilling fluid engineering: a review. J Pet Sci Eng 167:300-315. https://doi. org/10.1016/j.petrol.2018.04.019

33. Haleem A, Javaid M, Khan IH (2019) Current status and applications of Artificial Intelligence (AI) in medical field: an overview. Curr Med Res Pract. https://doi.org/10.1016/j.cmrp.2019.11.005

34. Wang H, Chaffart D, Ricardez-Sandoval LA (2019) Modelling and optimization of a pilot-scale entrained-flow gasifier using artificial neural networks. Energy 188:116076. https://doi.org/ 10.1016/j.energy.2019.116076

35. Kartheeswaran S, Christopher Durairaj DD (2017) A data-parallelism approach for PSO-ANN based medical image reconstruction on a multi-core system. Informatics Med Unlocked. https:// doi.org/10.1016/j.imu.2017.05.001

36. Ferreira LB, da Cunha FF, de Oliveira RA, Fernandes Filho EI (2019) Estimation of reference evapotranspiration in Brazil with limited meteorological data using ANN and SVM-a new approach. J Hydrol. https://doi.org/10.1016/j.jhydrol.2019.03. 028

37. Falat L, Pancikova L (2015) Quantitative modelling in economics with advanced artificial neural networks. Procedia Econ Financ. https://doi.org/10.1016/s2212-5671(15)01619-6

38. Dwivedi YK, Hughes L, Ismagilova E et al (2019) Artificial Intelligence (AI): multidisciplinary perspectives on emerging challenges, opportunities, and agenda for research, practice and policy. Int J Inf Manage. https://doi.org/10.1016/j.ijinfomgt.2019. 08.002

39. Kalogirou SA (2001) Artificial neural networks in renewable energy systems applications: a review. Renew Sustain Energy Rev 5:373-401

40. Haykin S (1994) Neural networks: a comprehensive foundation. Macmillan. https://doi.org/10.1017/S0269888998214044

41. Huang A, Zhang X, Li R, Chi Y (2018) Memristor neural network design. Memristor Memristive Neural Netw. https://doi.org/ 10.5772/intechopen.69929

42. Roy S, Banerjee R, Bose PK (2014) Performance and exhaust emissions prediction of a CRDI assisted single cylinder diesel engine coupled with EGR using artificial neural network. Appl Energy 119:330-340. https://doi.org/10.1016/j.apenergy.2014. 01.044

43. Meireles MR, Almeida PE, Simões MG (2003) A comprehensive review for industrial applicability of ANNs. IEEE Trans Ind Electron 50:585-601
44. Uzun A (2012) A parametric study for specific fuel consumption of an intercooled diesel engine using a neural network. Fuel 93:189-199. https://doi.org/10.1016/j.fuel.2011.11.004

45. Shivakumar, Srinivasa Pai P, Shrinivasa Rao BR et al (2011) Artificial Neural Network based prediction of performance and emission characteristics of a variable compression ratio $\mathrm{CI}$ engine using $\mathrm{WCO}$ as a biodiesel at different injection timings. Appl Energy 88:2344-2354. https://doi.org/10.1016/j.apenergy. 2010.12.030

46. Choi Y, Chen JY (2005) Fast prediction of start-of-combustion in HCCI with combined artificial neural networks and ignition delay model. Proc Combust Inst 30(2):2711-2718. https://doi. org/10.1016/j.proci.2004.08.143

47. Parlak A (2006) Application of artificial neural network to predict specific fuel consumption and exhaust temperature for a Diesel engine. Appl Therm Eng 26:824-828. https://doi.org/10. 1016/j.applthermaleng.2005.10.006

48. Arcakliog E (2005) Performance maps of a diesel engine. Appl Energy 81:247-259. https://doi.org/10.1016/j.apenergy.2004.08. 003

49. Zweiri YH, Seneviratne LD (2007) Diesel engine indicated torque estimation based on artificial neural networks, pp 791-798

50. Ghobadian B, Rahimi H, Nikbakht AM et al (2009) Diesel engine performance and exhaust emission analysis using waste cooking biodiesel fuel with an artificial neural network. Renew Energy 34:976-982. https://doi.org/10.1016/j.renene.2008.08.008

51. Yusaf TFTFF, Yousif BFF, Elawad MM et al (2015) Prediction and reduction of diesel engine emissions using a combined ANN-ACO method. Appl Energy 38:139-150. https://doi.org/ 10.1016/j.asoc.2015.04.059

52. Hemeida AM, Hassan SA, Mohamed AAA et al (2020) Natureinspired algorithms for feed-forward neural network classifiers: a survey of one decade of research. Ain Shams Eng J. https://doi. org/10.1016/j.asej.2020.01.007

53. Kaviani S, Sohn I (2020) Influence of random topology in artificial neural networks: A survey. ICT Express. https://doi.org/10. 1016/j.icte.2020.01.002

54. Kalogirou SA (2003) Artificial intelligence for the modeling and control of combustion processes : a review. Progress Energy Combust Sci 29(6):515-566

55. Kara Togun N, Baysec S (2010) Prediction of torque and specific fuel consumption of a gasoline engine by using artificial neural networks. Appl Energy 87:349-355. https://doi.org/10.1016/j. apenergy.2009.08.016

56. Cay Y (2013) Prediction of a gasoline engine performance with artificial neural network. Fuel 111:324-331. https://doi.org/10. 1016/j.fuel.2012.12.040

57. Şahin F (2015) Effects of engine parameters on ionization current and modeling of excess air coefficient by artificial neural network. Appl Therm Eng 90:94-101. https://doi.org/10.1016/j. applthermaleng.2015.06.100

58. Gölc̈u M, Sekmen Y, Erduranli P, Salman MS (2005) Artificial neural-network based modeling of variable valve-timing in a spark-ignition engine. Appl Energy 81:187-197. https://doi.org/ 10.1016/j.apenergy.2004.07.008

59. Hazar H, Gul H (2016) Modeling analysis of chrome carbide $(\mathrm{Cr} 3 \mathrm{C} 2)$ coating on parts of combustion chamber of a SI engine. Energy 115:76-87. https://doi.org/10.1016/j.energy.2016.08.083

60. Çay Y, Çiçek A, Kara F, Sağiroğlu S (2012) Prediction of engine performance for an alternative fuel using artificial neural network. Appl Therm Eng 37:217-225. https://doi.org/10.1016/j. applthermaleng.2011.11.019

61. Çay Y, Korkmaz I, Çiçek A, Kara F (2013) Prediction of engine performance and exhaust emissions for gasoline and methanol using artificial neural network. Energy 50:177-186. https://doi. org/10.1016/j.energy.2012.10.052 
62. Kapusuz M, Ozcan H, Ahmad J (2015) Research of performance on a spark ignition engine fueled by alcohol e gasoline blends using arti fi cial neural networks. Appl Therm Eng 91:525-534. https://doi.org/10.1016/j.applthermaleng.2015.08.058

63. Deh Kiani MK, Ghobadian B, Tavakoli T et al (2010) Application of artificial neural networks for the prediction of performance and exhaust emissions in SI engine using ethanol- gasoline blends. Energy 35:65-69. https://doi.org/10.1016/j.energy. 2009.08.034

64. Najafi G, Ghobadian B, Tavakoli T et al (2009) Performance and exhaust emissions of a gasoline engine with ethanol blended gasoline fuels using artificial neural network. Appl Energy 86:630-639. https://doi.org/10.1016/j.apenergy.2008.09.017

65. Yu HS, Arcakliog E (2007) Comparative study of mathematical and experimental analysis of spark ignition engine performance used ethanol-gasoline blend fuel. Appl Therm Eng 27:358-368. https://doi.org/10.1016/j.applthermaleng.2006.07.027

66. Danaiah P, Kumar PR, Rao YVH (2013) Performance and emission prediction of a tert butyl alcohol gasoline blended sparkignition engine using artificial neural networks. Int J Ambient Energy 36:37-41. https://doi.org/10.1080/01430750.2013. 820147

67. Sayin C, Ertunc HM, Hosoz M et al (2007) Performance and exhaust emissions of a gasoline engine using artificial neural network. Appl Therm Eng 27:46-54. https://doi.org/10.1016/j. applthermaleng.2006.05.016

68. Mehra RK, Duan H, Luo S et al (2018) Experimental and artificial neural network (ANN) study of hydrogen enriched compressed natural gas ( $\mathrm{HCNG}$ ) engine under various ignition timings and excess air ratios. Appl Energy 228:736-754. https://doi. org/10.1016/j.apenergy.2018.06.085

69. Tasdemir S, Saritas I, Ciniviz M, Allahverdi N (2011) Artificial neural network and fuzzy expert system comparison for prediction of performance and emission parameters on a gasoline engine. Expert Syst Appl 38:13912-13923. https://doi.org/10. 1016/j.eswa.2011.04.198

70. Tosun E, Aydin K, Merola SS, Irimescu A (2017) Estimation of operational parameters for a direct injection turbocharged spark ignition engine by using regression analysis and artificial neural network. Therm Sci. https://doi.org/10.2298/TSCI160302151T

71. Zheng T, Zhang Y, Li Y, Shi L (2019) Real-time combustion torque estimation and dynamic misfire fault diagnosis in gasoline engine. Mech Syst Signal Process 126:521-535. https://doi.org/ 10.1016/j.ymssp.2019.02.048

72. Jo Y, Min K, Jung D et al (2019) Comparative study of the artificial neural network with three hyper-parameter optimization methods for the precise LP-EGR estimation using in-cylinder pressure in a turbocharged GDI engine. Appl Therm Eng 149:1324-1334. https://doi.org/10.1016/j.applthermaleng.2018. 12.139

73. Martínez-Morales J, Quej-Cosgaya H, Lagunas-Jiménez J et al (2019) Design optimization of multilayer perceptron neural network by ant colony optimization applied to engine emissions data. Sci China Technol Sci 62:1055-1064. https://doi.org/10. 1007/s11431-017-9235-y

74. Uslu S, Celik MB (2020) Performance and exhaust emission prediction of a SI engine fueled with I-amyl alcohol-gasoline blends: an ANN coupled RSM based optimization. Fuel 265:116922. https://doi.org/10.1016/j.fuel.2019.116922

75. Liu W, Safdari Shadloo M, Tlili I et al (2020) The effect of alcohol-gasoline fuel blends on the engines' performances and emissions. Fuel 276:117977. https://doi.org/10.1016/j.fuel.2020. 117977

76. Çelik V, Arcaklioğlu E (2005) Performance maps of a diesel engine. Appl Energy 81:247-259. https://doi.org/10.1016/j.apene rgy.2004.08.003
77. Siami-Irdemoosa E, Dindarloo SR (2015) Prediction of fuel consumption of mining dump trucks: a neural networks approach. Appl Energy 151:77-84. https://doi.org/10.1016/j.apenergy. 2015.04.064

78. Bietresato M, Calcante A, Mazzetto F (2015) A neural network approach for indirectly estimating farm tractors engine performances. Fuel 143:144-154. https://doi.org/10.1016/j.fuel.2014. 11.019

79. Goudarzi K, Moosaei A, Gharaati M (2015) Applying artificial neural networks (ANN) to the estimation of thermal contact conductance in the exhaust valve of internal combustion engine. Appl Therm Eng 87:688-697. https://doi.org/10.1016/j.applt hermaleng.2015.05.060

80. Arcaklioğlu E, Çelıkten İ (2005) A diesel engine's performance and exhaust emissions. Appl Energy 80:11-22. https://doi.org/ 10.1016/j.apenergy.2004.03.004

81. Nikzadfar K, Shamekhi AH (2014) Investigating the relative contribution of operational parameters on performance and emissions of a common-rail diesel engine using neural network. Fuel 125:116-128. https://doi.org/10.1016/j.fuel.2014.02.021

82. Muralidharan K, Vasudevan D (2014) Applications of artificial neural networks in prediction of performance, emission and combustion characteristics of variable compression ratio engine fuelled with waste cooking oil biodiesel. J Braz Soc Mech Sci Eng 37:915-928. https://doi.org/10.1007/s40430-014-0213-4

83. Gürgen S, Ünver B, Altın İ (2018) Prediction of cyclic variability in a diesel engine fueled with n-butanol and diesel fuel blends using artificial neural network. Renew Energy 117:538-544. https://doi.org/10.1016/j.renene.2017.10.101

84. Arumugam S, Sriram G, Shankara Subramanian PR (2012) Application of artificial intelligence to predict the performance and exhaust emissions of diesel engine using rapeseed oil methyl ester. Procedia Eng 38:853-860. https://doi.org/10.1016/j.proeng.2012.06.107

85. Yusaf TF, Yousif BF, Elawad MM (2011) Crude palm oil fuel for diesel-engines: experimental and ANN simulation approaches. Energy 36:4871-4878. https://doi.org/10.1016/j.energy.2011.05. 032

86. Kshirsagar CM, Anand R (2017) Artificial neural network applied forecast on a parametric study of Calophyllum inophyllum methyl ester-diesel engine out responses. Appl Energy 189:555-567. https://doi.org/10.1016/j.apenergy.2016.12.045

87. Basurko OC, Uriondo Z (2015) Condition-based maintenance for medium speed diesel engines used in vessels in operation. Appl Therm Eng 80:404-412. https://doi.org/10.1016/j.appltherma leng.2015.01.075

88. Vinay Kumar D, Ravi Kumar P, Kumari MS (2013) Prediction of performance and emissions of a biodiesel fueled lanthanum zirconate coated direct injection diesel engine using artificial neural networks. Procedia Eng 64:993-1002. https://doi.org/10. 1016/j.proeng.2013.09.176

89. Lapuerta M, Rodrı J (2005) Neural networks estimation of diesel particulate matter composition from transesterified waste oils blends. Fuel 84:2080-2085. https://doi.org/10.1016/j.fuel.2005. 04.029

90. Oğuz H, Sarıtas I, Baydan HE (2010) Prediction of diesel engine performance using biofuels with artificial neural network. Expert Syst Appl 37:6579-6586. https://doi.org/10.1016/j.eswa.2010. 02.128

91. Ilangkumaran M, Sakthivel G, Nagarajan G (2016) Artificial neural network approach to predict the engine performance of fish oil biodiesel with diethyl ether using back propagation algorithm. Int J Ambient Energy 37:446-455. https://doi.org/10.1080/01430 750.2014.984082

92. Gharehghani A, Pourrahmani H (2019) Performance evaluation of diesel engines (PEDE) for a diesel-biodiesel fueled CI 
engine using nano-particles additive. Energy Convers Manag 198:111921. https://doi.org/10.1016/j.enconman.2019.111921

93. Soukht Saraee H, Taghavifar H, Jafarmadar S (2017) Experimental and numerical consideration of the effect of $\mathrm{CeO} 2$ nanoparticles on diesel engine performance and exhaust emission with the aid of artificial neural network. Appl Therm Eng 113:663-672. https://doi.org/10.1016/j.applthermaleng.2016. 11.044

94. Manieniyan V, Vinodhini G, Senthilkumar R, Sivaprakasam S (2016) Wear element analysis using neural networks of a DI diesel engine using biodiesel with exhaust gas recirculation. Energy 114:603-612. https://doi.org/10.1016/j.energy.2016.08.040

95. Hosseini SH, Taghizadeh-Alisaraei A, Ghobadian B, Abbaszadeh-Mayvan A (2020) Artificial neural network modeling of performance, emission, and vibration of a CI engine using alumina nano-catalyst added to diesel-biodiesel blends. Renew Energy 149:951-961. https://doi.org/10.1016/j.renene.2019.10.080

96. Shanmugam P, Sivakumar V, Murugesan A, Ilangkumaran M (2011) Performance and exhaust emissions of a diesel engine using hybrid fuel with an artificial neural network. Energy Sources Part A Recover Util Environ Eff 33:1440-1450. https:// doi.org/10.1080/15567036.2010.539085

97. Sakthivel G, Ilangkumaran M, Nagarajan G (2012) Predicting the engine performance using ethyl ester of fish oil with the aid of artificial neural network. Int J Ambient Energy 34:145-158. https://doi.org/10.1080/01430750.2012.740429

98. Shrivastava P, Salam S, Verma TN, Samuel OD (2020) Experimental and empirical analysis of an IC engine operating with ternary blends of diesel, karanja and roselle biodiesel. Fuel 262:116608. https://doi.org/10.1016/j.fuel.2019.116608

99. Mohamed Ismail H, Ng HK, Queck CW et al (2012) Artificial neural networks modelling of engine-out responses for a lightduty diesel engine fuelled with biodiesel blends. Appl Energy 92:769-777. https://doi.org/10.1016/j.apenergy.2011.08.027

100. Canakci M, Erdil A, Arcaklioğlu E (2006) Performance and exhaust emissions of a biodiesel engine. Appl Energy 83:594605. https://doi.org/10.1016/j.apenergy.2005.05.003

101. Canakci M, Necati A, Arcaklioglu E, Erdil A (2009) Expert systems with applications prediction of performance and exhaust emissions of a diesel engine fueled with biodiesel produced from waste frying palm oil. Expert Syst Appl 36:9268-9280. https:// doi.org/10.1016/j.eswa.2008.12.005

102. Taghavifar H, Taghavifar H, Mardani A et al (2014) Appraisal of artificial neural networks to the emission analysis and prediction of $\mathrm{CO} 2$, soot, and NOx of n-heptane fueled engine. J Clean Prod. https://doi.org/10.1016/j.jclepro.2015.03.035

103. Taghavifar H, Taghavifar H, Mardani A et al (2015) A numerical investigation on the wall heat flux in a di diesel engine fueled with n-heptane using a coupled CFD and ANN approach. Fuel 140:227-236. https://doi.org/10.1016/j.fuel.2014.09.092

104. Salam S, Verma TN (2019) Appending empirical modelling to numerical solution for behaviour characterisation of microalgae biodiesel. Energy Convers Manag 180:496-510. https://doi.org/ 10.1016/j.enconman.2018.11.014

105. Çelebi K, Uludamar E, Tosun E et al (2017) Experimental and artificial neural network approach of noise and vibration characteristic of an unmodified diesel engine fuelled with conventional diesel, and biodiesel blends with natural gas addition. Fuel 197:159-173. https://doi.org/10.1016/j.fuel.2017.01.113

106. Akkouche N, Loubar K, Nepveu F et al (2020) Micro-combined heat and power using dual fuel engine and biogas from discontinuous anaerobic digestion. Energy Convers Manag 205:112407. https://doi.org/10.1016/j.enconman.2019.112407

107. Javed S, Baig RU, Murthy YVVS (2018) Study on noise in a hydrogen dual-fuelled zinc-oxide nanoparticle blended biodiesel engine and the development of an artificial neural network model. Energy 160:774-782. https://doi.org/10.1016/j.energy. 2018.07.041

108. Javed S, Murthy YVVS, Ulla R, Rao DP (2015) Development of ANN model for prediction of performance and emission characteristics of hydrogen dual fueled diesel engine with Jatropha Methyl Ester biodiesel blends. J Nat Gas Sci Eng 26:549-557. https://doi.org/10.1016/j.jngse.2015.06.041

109. Yusaf TF, Buttsworth DR, Saleh KH, Yousif BF (2010) CNGdiesel engine performance and exhaust emission analysis with the aid of artificial neural network. Appl Energy 87:1661-1669. https://doi.org/10.1016/j.apenergy.2009.10.009

110. Uludamar E, Tosun E, Tüccar G et al (2017) Evaluation of vibration characteristics of a hydroxyl (HHO) gas generator installed diesel engine fuelled with different diesel-biodiesel blends. Int J Hydrogen Energy 42:23352-23360. https://doi.org/10.1016/j. ijhydene.2017.01.192

111. Syed J, Baig RU, Algarni S et al (2017) Artificial Neural Network modeling of a hydrogen dual fueled diesel engine characteristics: an experiment approach. Int J Hydrogen Energy 42:14750 14774. https://doi.org/10.1016/j.ijhydene.2017.04.096

112. Taghavifar H, Taghavifar H, Mardani A et al (2015) On the modeling of convective heat transfer coefficient of hydrogen fueled diesel engine as affected by combustion parameters using a coupled numerical-artificial neural network approach. Int J Hydrogen Energy 40:4370-4381. https://doi.org/10.1016/j.ijhydene. 2015.01.140

113. Esonye C, Onukwuli OD, Ofoefule AU, Ogah EO (2019) Multiinput multi-output (MIMO) ANN and Nelder-Mead's simplex based modeling of engine performance and combustion emission characteristics of biodiesel-diesel blend in CI diesel engine. Appl Therm Eng. https://doi.org/10.1016/j.applthermaleng.2019.01. 101

114. Shamshirband S, Tabatabaei M, Aghbashlo M et al (2016) Support vector machine-based exergetic modelling of a di diesel engine running on biodiesel-diesel blends containing expanded polystyrene. Appl Therm Eng 94:727-747. https://doi.org/10. 1016/j.applthermaleng.2015.10.140

115. Yıldırım S, Tosun E, Çalık A et al (2019) Artificial intelligence techniques for the vibration, noise, and emission characteristics of a hydrogen-enriched diesel engine. Energy Sources Part A Recover Util Environ Eff. https://doi.org/10.1080/15567036. 2018.1550540

116. Redel-Macías MD, Hervás-Martínez C, Gutiérrez PA et al (2018) Computational models to predict noise emissions of a diesel engine fueled with saturated and monounsaturated fatty acid methyl esters. Energy 144:110-119. https://doi.org/10.1016/j. energy.2017.11.143

117. Aghbashlo M, Shamshirband S, Tabatabaei M et al (2016) The use of ELM-WT (extreme learning machine with wavelet transform algorithm) to predict exergetic performance of a DI diesel engine running on diesel/biodiesel blends containing polymer waste. Energy 94:443-456. https://doi.org/10.1016/j.energy. 2015.11.008

118. Rahimi molkdaragh R, Jafarmadar S, Khalilaria S, Soukht Saraee $\mathrm{H}$, (2018) Prediction of the performance and exhaust emissions of a compression ignition engine using a wavelet neural network with a stochastic gradient algorithm. Energy 142:1128-1138. https://doi.org/10.1016/j.energy.2017.09.006

119. Roy S, Ghosh A, Das AK, Banerjee R (2015) Development and validation of a GEP model to predict the performance and exhaust emission parameters of a CRDI assisted single cylinder diesel engine coupled with EGR. Appl Energy 140:52-64. https://doi.org/10.1016/j.apenergy.2014.11.065

120. Domínguez-Sáez A, Rattá GA, Barrios CC (2018) Prediction of exhaust emission in transient conditions of a diesel engine fueled with animal fat using Artificial Neural Network and 
Symbolic Regression. Energy 149:675-683. https://doi.org/10. 1016/j.energy.2018.02.080

121. Etghani MM, Shojaeefard MH, Khalkhali A, Akbari M (2013) A hybrid method of modified NSGA-II and TOPSIS to optimize performance and emissions of a diesel engine using biodiesel. Appl Therm Eng 59:309-315. https://doi.org/10.1016/j. applthermaleng.2013.05.041

122. Krishnamoorthi M, Malayalamurthi R, Sakthivel R (2019) Optimization of compression ignition engine fueled with diesel-chaulmoogra oil-diethyl ether blend with engine parameters and exhaust gas recirculation. Renew Energy 134:579602. https://doi.org/10.1016/j.renene.2018.11.062

123. Krishnamoorthi M, Malayalamurthi R (2018) Engine characteristics analysis of chaulmoogra oil blends and corrosion analysis of injector nozzle using scanning electron microscopy/energy dispersive spectroscopy. Energy 165:1292-1319. https://doi.org/10.1016/j.energy.2018.10.112

124. Channapattana SV, Pawar AA, Kamble PG (2017) Optimisation of operating parameters of DI-CI engine fueled with second generation Bio-fuel and development of ANN based prediction model. Appl Energy 187:84-95. https://doi.org/10.1016/j. apenergy.2016.11.030

125. Bhowmik S, Paul A, Panua R et al (2018) Performance-exhaust emission prediction of diesosenol fueled diesel engine: An ANN coupled MORSM based optimization. Elsevier

126. Roy S, Das AK, Bose PK, Banerjee R (2014) ANN metamodel assisted Particle Swarm Optimization of the performanceemission trade-off characteristics of a single cylinder CRDI engine under CNG dual-fuel operation. J Nat Gas Sci Eng 21:1156-1162. https://doi.org/10.1016/j.jngse.2014.11.013

127. Banerjee R, Mikulski M, Chakraborty A et al (2017) ANN meta-model assisted MOPSO application in an EPA-Tier 4 constrained emission-performance trade-off calibration problem of a hydrogen-diesel-EGR dual fuel operation. Fuel 208:746-778. https://doi.org/10.1016/j.fuel.2017.07.037

128. Deb M, Majumder P, Majumder A et al (2016) Application of artificial intelligence (AI) in characterization of the performance-emission profile of a single cylinder CI engine operating with hydrogen in dual fuel mode: an ANN approach with fuzzy-logic based topology optimization. Int J Hydrogen Energy 41:14330-14350. https://doi.org/10.1016/j.ijhydene. 2016.07.016

129. Lotfan S, Ghiasi RA, Fallah M, Sadeghi MH (2016) ANN-based modeling and reducing dual-fuel engine's challenging emissions by multi-objective evolutionary algorithm NSGA-II. Appl Energy 175:91-99. https://doi.org/10.1016/j.apenergy.2016.04. 099
130. Babu D, Thangarasu V, Ramanathan A (2020) Artificial neural network approach on forecasting diesel engine characteristics fuelled with waste frying oil biodiesel. Appl Energy. https://doi. org/10.1016/j.apenergy.2020.114612

131. Aydın M, Uslu S, Bahattin Çelik M (2020) Performance and emission prediction of a compression ignition engine fueled with biodiesel-diesel blends: a combined application of ANN and RSM based optimization. Fuel. https://doi.org/10.1016/j.fuel. 2020.117472

132. Hariharan N, Senthil V, Krishnamoorthi M, Karthic SV (2020) Application of artificial neural network and response surface methodology for predicting and optimizing dual-fuel CI engine characteristics using hydrogen and bio fuel with water injection. Fuel 270:117576. https://doi.org/10.1016/j.fuel.2020.117576

133. Bahri B, Shahbakhti M, Aziz AA (2017) Real-time modeling of ringing in $\mathrm{HCCI}$ engines using artificial neural networks. Energy 125:509-518. https://doi.org/10.1016/j.energy.2017.02.137

134. Bahri B, Aziz AA, Shahbakhti M, Muhamad Said MF (2013) Understanding and detecting misfire in an HCCI engine fuelled with ethanol. Appl Energy 108:24-33. https://doi.org/10.1016/j. apenergy.2013.03.004

135. Bahri B, Shahbakhti M, Kannan K, Aziz AA (2016) Identification of ringing operation for low temperature combustion engines. Appl Energy 171:142-152. https://doi.org/10.1016/j. apenergy.2016.03.033

136. Rezaei J, Shahbakhti M, Bahri B, Aziz AA (2015) Performance prediction of HCCI engines with oxygenated fuels using artificial neural networks. Appl Energy 138:460-473. https://doi.org/10. 1016/j.apenergy.2014.10.088

137. Maurya RK, Saxena MR (2018) Characterization of ringing intensity in a hydrogen-fueled HCCI engine. Int J Hydrogen Energy 43:9423-9437. https://doi.org/10.1016/j.ijhydene.2018. 03.194

138. Taghavi M, Gharehghani A, Nejad FB, Mirsalim M (2019) Developing a model to predict the start of combustion in HCCI engine using ANN-GA approach. Energy Convers Manag 195:57-69. https://doi.org/10.1016/j.enconman.2019.05.015

139. Anarghya A, Rao N, Nayak N et al (2018) Optimized ANN-GA and experimental analysis of the performance and combustion characteristics of HCCI engine. Appl Therm Eng 132:841-868. https://doi.org/10.1016/j.applthermaleng.2017.12.129

Publisher's Note Springer Nature remains neutral with regard to jurisdictional claims in published maps and institutional affiliations. 